\title{
Benefit Inequality among American Workers by Gender, Race, and Ethnicity, 1982-2015
}

\author{
Tali Kristal, ${ }^{a}$ Yinon Cohen, ${ }^{b}$ Edo Navot ${ }^{\mathrm{c}}$
}

a) University of Haifa; b) Columbia University; c) United States Department of Labor

Abstract: Gender, racial, and ethnic gaps in wages are well known, but group disparities in employerprovided benefits, which account for one-quarter of total compensation, are not. We use benefit costs data to study levels and trends in gender, racial, and ethnic gaps in voluntary employer-provided benefits. Analyzing Employer Costs for Employee Compensation microdata on wages and benefit costs for the years 1982 to 2015, matched to Current Population Survey files by wage decile in the industrial sector, we find that (1) benefit gaps were wider than wage gaps for minorities but were narrower for gender, (2) racial and ethnic gaps in benefits increased faster than wage gaps, and (3) the gender gap in benefits decreased faster than the wage gap. We show that these findings reflect the types of jobs women, blacks, and Hispanics have held for the past three decades.

Keywords: employer-provided benefits; inequality; gender; race; ethnicity; jobs

Citation: Kristal, Tali, Yinon Cohen, and Edo Navot. 2018. "Benefit Inequality among American Workers by Gender, Race and Ethnicity, 1982-2015." Sociological Science 5: 461-488.

Received: April 17, 2018

Accepted: June 5, 2018

Published: July 19, 2018

Editor(s): Jesper Sørensen, Kim Weeden

DOI: $10.15195 /$ v5.a20

Copyright: (C) 2018 The Author(s). This open-access article has been published under a Creative Commons Attribution License, which allows unrestricted use, distribution and reproduction, in any form, as long as the original author and source have been credited. (C) (i)
$\mathrm{W}$ OMEN and racial or ethnic minorities consistently draw lower wages than do white men. But wages are only one source of labor market-based income inequality, particularly in the United States, which represents the quintessential case of private social benefits. In 2015, voluntary (not legally required) employerprovided benefits accounted for 25 percent of total employer compensation costs; pension plans, health insurance, and paid leave, which are primarily obtained through employment, accounted for 21 percent (Figure 1). ${ }^{1}$ Because employerprovided benefits represent a significant and growing share of total (pecuniary) compensation for American workers, the men-women wage gap, the white-black wage gap, and the white-Hispanic wage gap might underestimate or overestimate total compensation inequality, depending on how the distribution of benefits compares with the distribution of wages.

Here, we extend analyses of gender- and race-based labor market inequality beyond wages to inequality in voluntary employer-provided benefits. We do this by providing the first rigorous description of the dynamics of benefit costs by gender, race, and ethnicity since 1982. Studies on the dollar value of benefits that are available to a worker are scarce, as this kind of data is difficult to obtain, but a few studies on employer costs of benefits exist. In the United States, most were by Pierce $(2001,2010)$ and based on Bureau of Labor Statistics (BLS) data, which are only available as job-level averages without information on gender or race. Therefore, we do not know the basic facts regarding gender, racial, and ethnic gaps in the level of employer-provided benefits as compared with wage gaps nor how much these gaps have changed in recent decades.

We address this lacuna by imputing data from the BLS Employer Costs for Employee Compensation (ECEC) on benefit costs by wage decile in eight industrial 


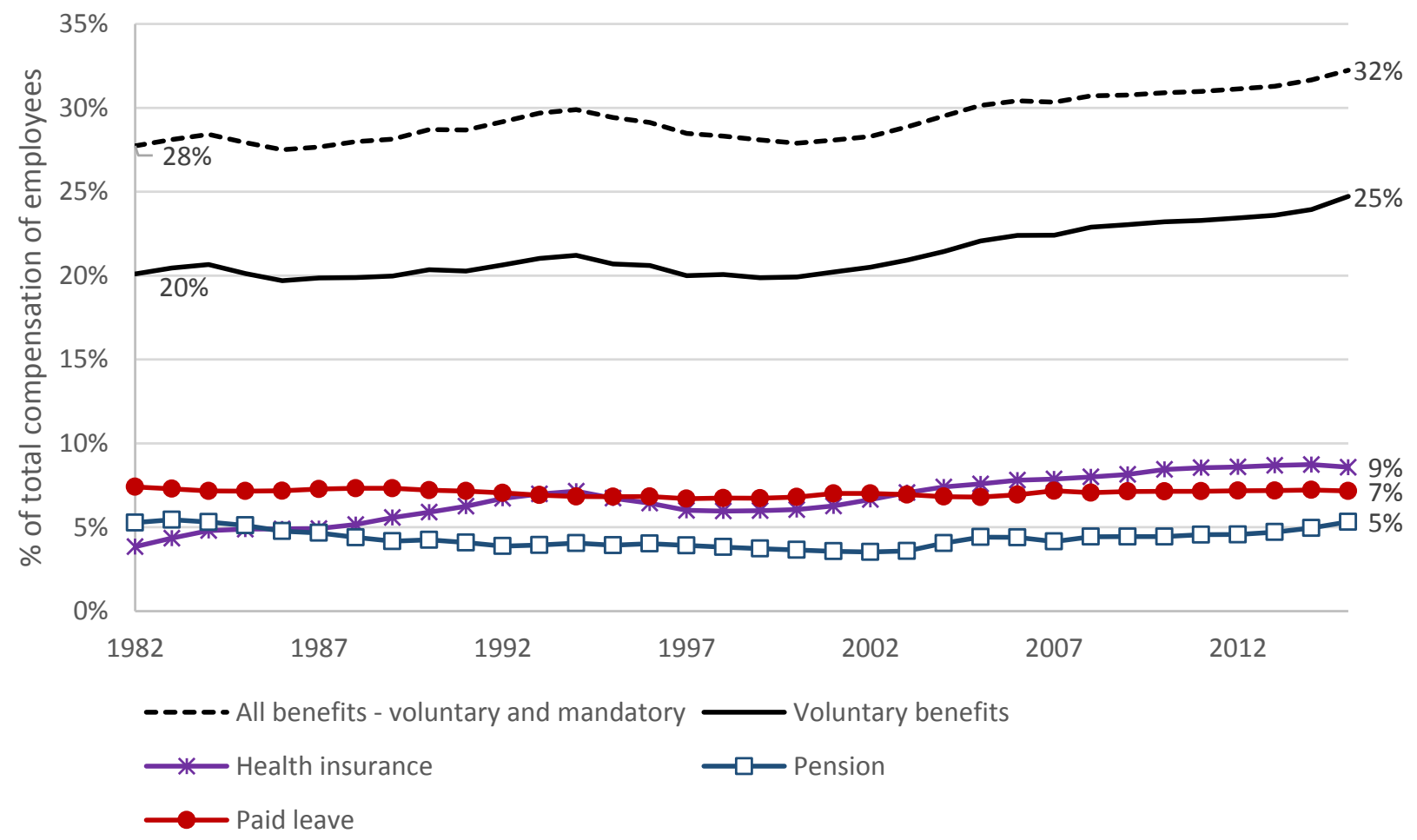

Figure 1: Voluntary and mandatory supplements to wages and salaries as a percentage of the total compensation of employees, 1982-2015. Notes: Data are derived from Bureau of Labor Statistics (BLS) "Employer Costs for Employee Compensation" (ECEC). Voluntary benefits include health insurance, life insurance, sickness and accident insurance, pension (defined benefit pensions and defined contribution plans), paid leave (vacations, holidays, sick leave, and other paid leave), supplemental pay (nonproduction bonuses), and other benefits (severance pay, supplemental unemployment plans, and merchandise discounts in department stores). Mandatory benefits include Social Security, Medicare, worker's compensation, and state and federal unemployment insurance.

sectors to individual-level data from the Current Population Survey Annual Social and Economic Supplement (CPS-ASEC) files yearly for 1982 to 2015. This method makes it possible to develop proxy estimates for the dollar value of benefit costs for each worker. Previous studies have made few attempts to impute aggregate data on benefits costs to the CPS's individual-level data. Hersch and White-Means (1993) and Chung (2003) merged aggregate data on benefit costs by 21 industry groups from the Chamber of Commerce Employee Benefits Survey (EBS), in which 1,000 companies voluntarily participated in the early 1990s (this number fell to 400 companies in the 2000s), with the use of the CPS's individual-level data. For the years 1996 to 2008, Burkhauser and Simon (2010) merged aggregate data on health insurance costs by state, year, and firm size from the Medical Expenditure Panel Survey Insurance Component. Piketty, Saez, and Zucman (2016) took a somewhat different approach, allocating total nontaxable health and pension benefits each year from national accounts to individual workers based on information on benefit coverage in the CPS. 
Our study improves on these earlier works because it employs data from the ECEC nonpublic microdata, which are the best available for measuring benefit costs over time. They span a substantial period, contain information at the job level on the hourly employer cost of employee compensation (covering 23 benefit areas) for a representative national sample of jobs, reflect current employment distributions, and are derived from employer and administrative records. Also, we employ the matching procedure, which utilizes both the wage decile and industrial sector (against only industry groups or only state and firm sizes). Lastly, previous studies did not estimate levels and trends in benefit costs for various demographic groups.

For those who prefer some foreshadowing, we can reveal now that since the late 1990s, the gender gap in benefits has been lower than the wage gap. That is, for gender, benefit inequality decreased faster than wage inequality. By contrast, racial and ethnic gaps in benefits are wider than wage gaps, and benefit inequality has increased more than wage inequality in recent decades. Following the detailed description in the section on documenting gender, racial, and ethnic gaps in benefits, in the section on changes over time in gender, racial, and ethnic income gaps, we explain our analytical approach to understanding changes over time in group-based inequality. We differentiate three main components: changes in group-specific characteristics, changes in the overall wage structure (i.e., changes in returns on wage determinants), and other unmeasured changes grouped under "unexplained gaps." See Juhn, Murphy, and Pierce (1991) for the changing racial wage gap, Blau and Kahn (1997) and Cha and Weeden (2014) for the changing gender wage gap, and Haberfeld and Cohen (2007) for the changing national and ethnic gaps.

Our analytical strategy is two pronged: First, we describe groups' locations on the wage distribution and the associated benefits at various locations on this distribution during the last three decades (section on wage structure, social groups, and benefits). This shows that for a long time, ethnic minorities have been located at the bottom of the wage distribution, a place with lower and declining benefits. Next (section on decomposition of wage and benefit gaps), we present decompositions of wage and benefit gaps into the above three components, revealing that changes in group-based differences in education, work experience, occupation, and unionization, as well as the returns on them, affected benefits more than wages. These effects caused a more rapid enlargement of the benefit gap (compared with the wage gap) for ethnicity and race but not for gender, for which the benefit gap narrowed faster than the wage gap. In the discussion and conclusions, we suggest that the findings are the result of benefits being less sticky than wages at the bottom of the wage structure but being stickier than wages at the top.

\section{Documenting Gender, Racial, and Ethnic Gaps in Benefits}

\section{Benefit Coverage and Benefit Costs Based on CPS-ASEC}

We use information from (1) the CPS-ASEC (Figures 2 and 3; Table 1) and (2) the CPS-ASEC matched to the BLS-ECEC (Figures 4-6) to establish the facts on levels and trends with regard to gender, racial, and ethnic benefit gaps. We start the 
a. Gender

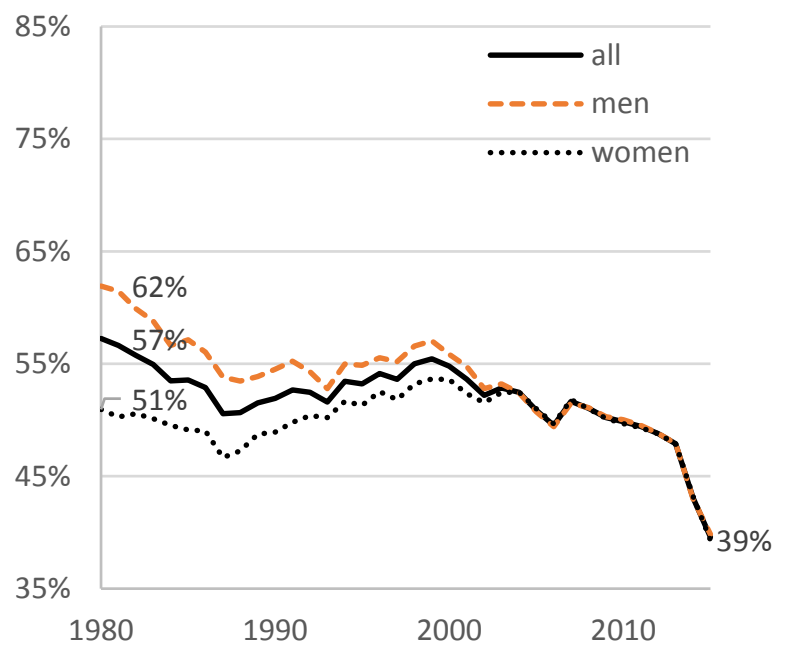

b. Race and/or ethnicity

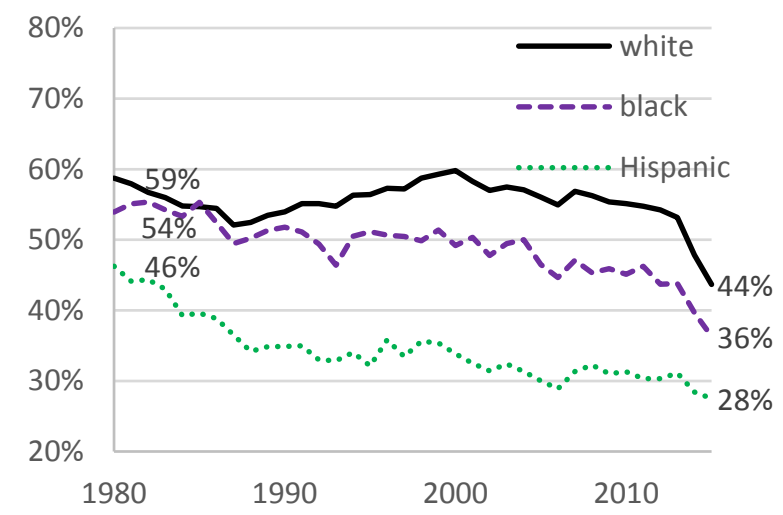

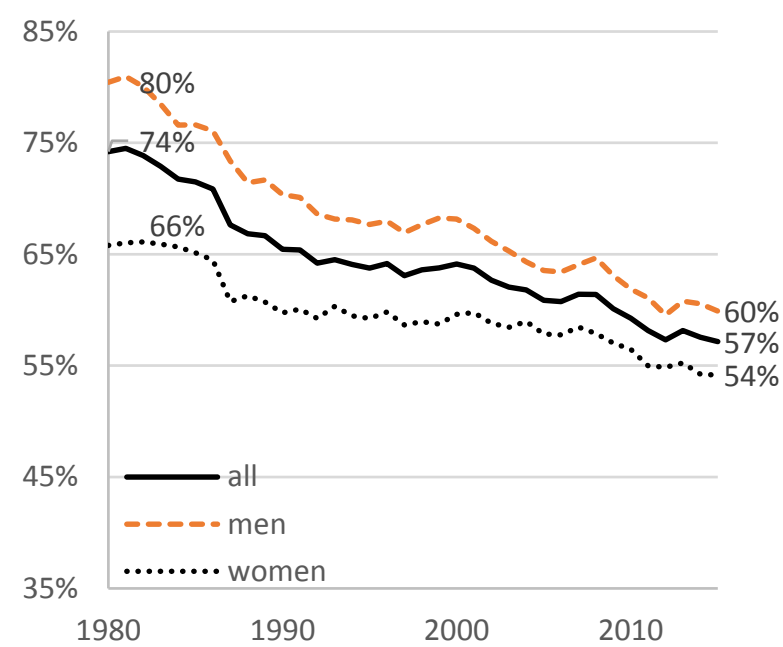

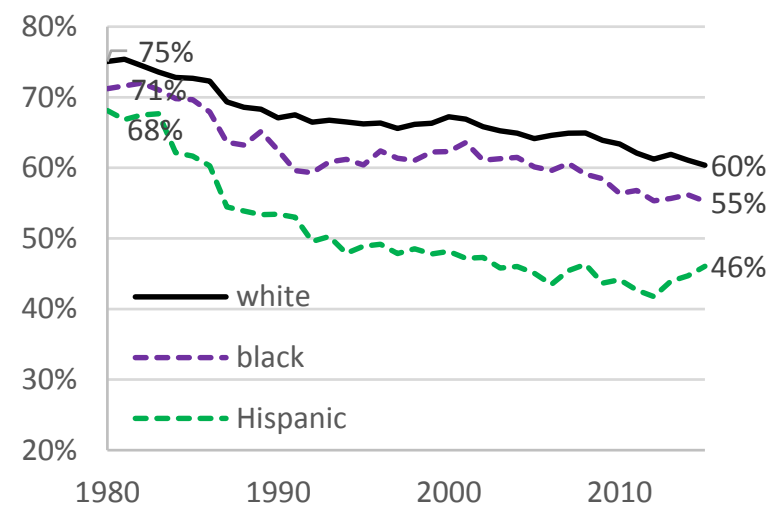

Figure 2: Employer-provided pension coverage (left) and employer-provided health insurance coverage (right) by gender and race and/or ethnicity, 1980-2015. Notes: Private industry (and state and local government sector) wage and salary workers aged 18 to 65 who worked at least 20 hours per week and 26 weeks per year. Coverage is defined as being included in an employer-provided plan for which the employer is paid at least some of the coverage. Race and/or ethnicity categories are mutually exclusive (i.e., white non-Hispanic, black non-Hispanic, and Hispanic any race).

description by presenting in Figure 2 trends in employer-provided pension and health insurance coverage for the years 1980 to 2015. Data are drawn from the CPSASEC's large and representative household data, which are the common source for data on employer-provided pension coverage and health insurance coverage. It identifies workers with pension and health insurance plans and determines whether that coverage is through the individual's employer. Because pension and health insurance coverage refer to the previous year, we use, for example, the 1981 data to measure benefit coverage in 1980. We use CPS-ASEC data samples from 1981 to 
2016 to compile a sample of wage and salary workers aged 18 to 65 . To focus on workers with strong labor force attachment, we limit our sample to wage and salary workers who worked at least 20 hours per week and at least 26 weeks in the previous year. ${ }^{2}$ Figures are shown for the population covered by the ECEC: workers who are employed in the nonagricultural private sector and state and local government sectors. Figures for all workers belonging to the nonagricultural civilian labor force, including those employed in the federal government (not shown), are closely similar. $^{3}$

The empirical trends reveal a somewhat unknown (except Levy 2006 and Mishel et al. 2012) and unsolved puzzle: gender convergence in benefit coverage. Men gradually lost their entire advantage in pension coverage, and by the early 2000s, men and women had the same odds of obtaining a pension from their employers (Figure 2a). From the early 2000s, pension coverage declined for both sexes, from 52 percent in 2003 to 39 percent in 2015. Whereas the entire decline in pension coverage during the 1980s and 1990s occurred among men, men and women experienced a fall in employer-provided health insurance. The decline in health insurance coverage, however, was much more severe for men (from 80 percent coverage in 1980 to 60 percent in 2015) than for women (from 66 percent coverage in 1980 to 54 percent in 2015). Consequentially, the women-to-men coverage gap decreased from about 14 percentage points in the early 1980s to only 6 percentage points in the 2000s. ${ }^{4}$

Although inequality in benefit coverage held less for gender, it was still very relevant for minorities (Semyonov, Lewin-Epstein, and Bridges 2011). Coverage rates for ethnic minorities, which were lower than those for whites at the beginning of the period, fell more sharply, in particular for Hispanics, who found themselves increasingly excluded from the primary source of health insurance and pension plans in the United States (Figure 2b). In 2015, only 28 percent of Hispanic workers were covered by an employer-provided pension, and fewer than half were covered by health insurance. The pattern of increasing benefit coverage inequality was most salient through the 1980s and 1990s, although in the last two decades, inequality stagnated as white workers also experienced a decline in benefit coverage, mostly in pensions.

Results for the intersections across gender, race, and ethnicity are presented in Table 1. Similar to previous research on earnings (Mandel and Semyonov 2016), racial and ethnic benefit coverage gaps for men were more pronounced than for women. Benefit coverage inequality was highest between Hispanic and white men. The trend between 1980 and 2015 shows that benefit coverage inequality, in both pensions and health insurance, increased for Hispanic men and women alike. Rising benefit coverage inequality in pensions was also substantial for black women, whereas for black men, it was less evident. All these changes occurred mainly through the 1980s and 1990s.

Being covered (or not) by employer-provided health insurance reveals only one part of total benefit inequality. The other part is the level of benefits obtained from the employer. Data on employer costs of benefits are rare. Since 1992, the CPS-ASEC files have included estimates for the sum of an employer's contribution to health insurance but not to pensions or other benefits. ${ }^{5}$ Figure 3 presents an 
a. Women-to-men

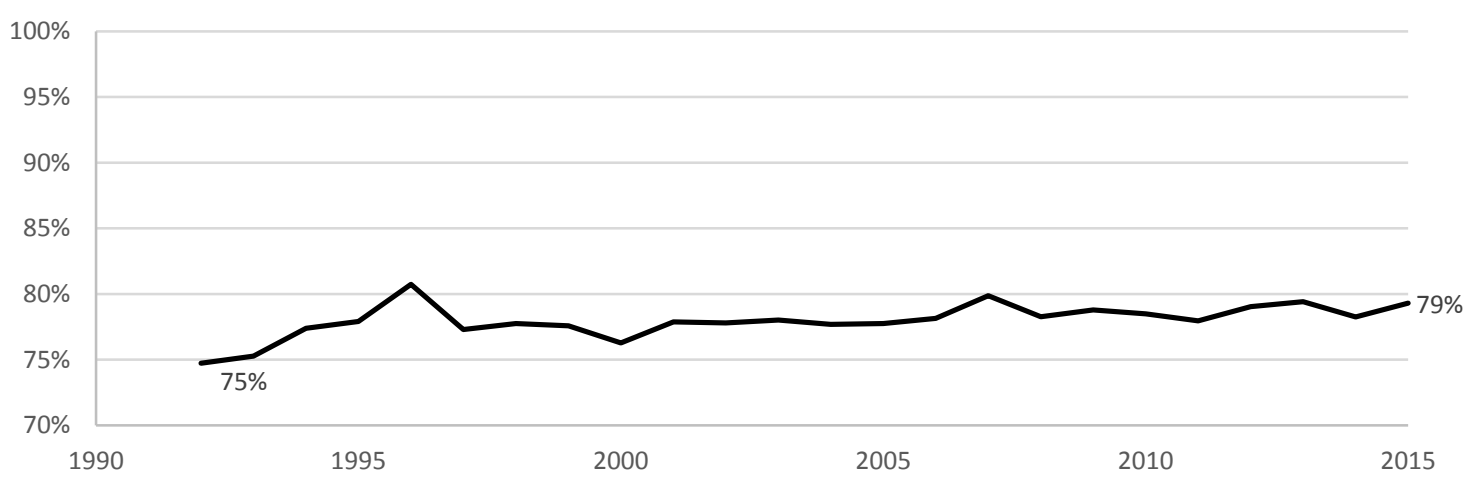

b. Men

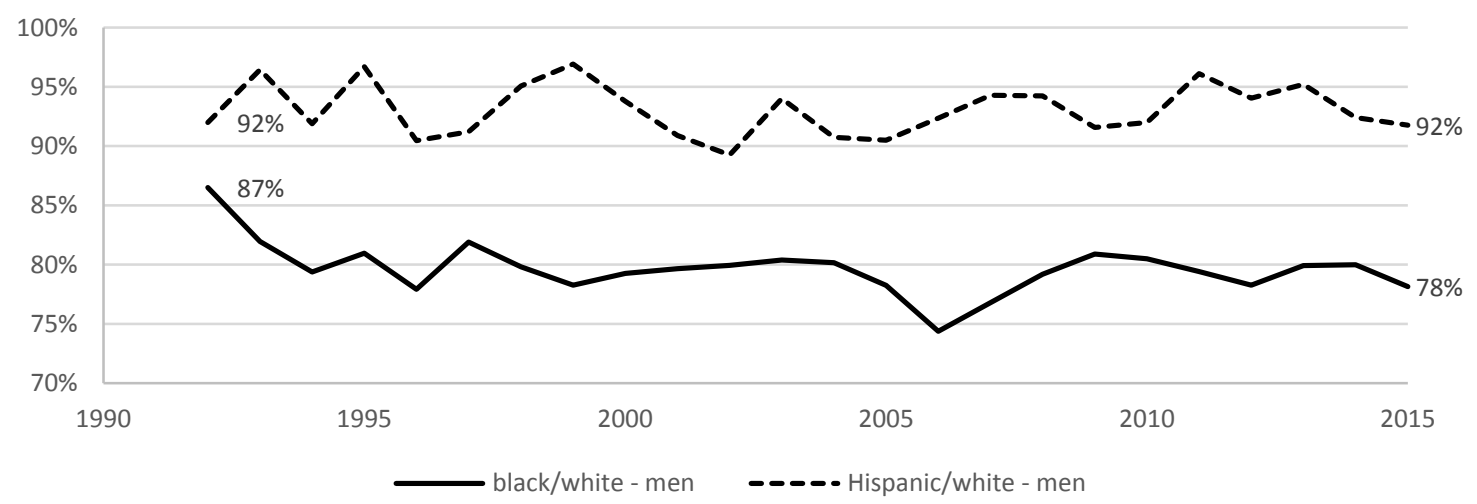

c. Women

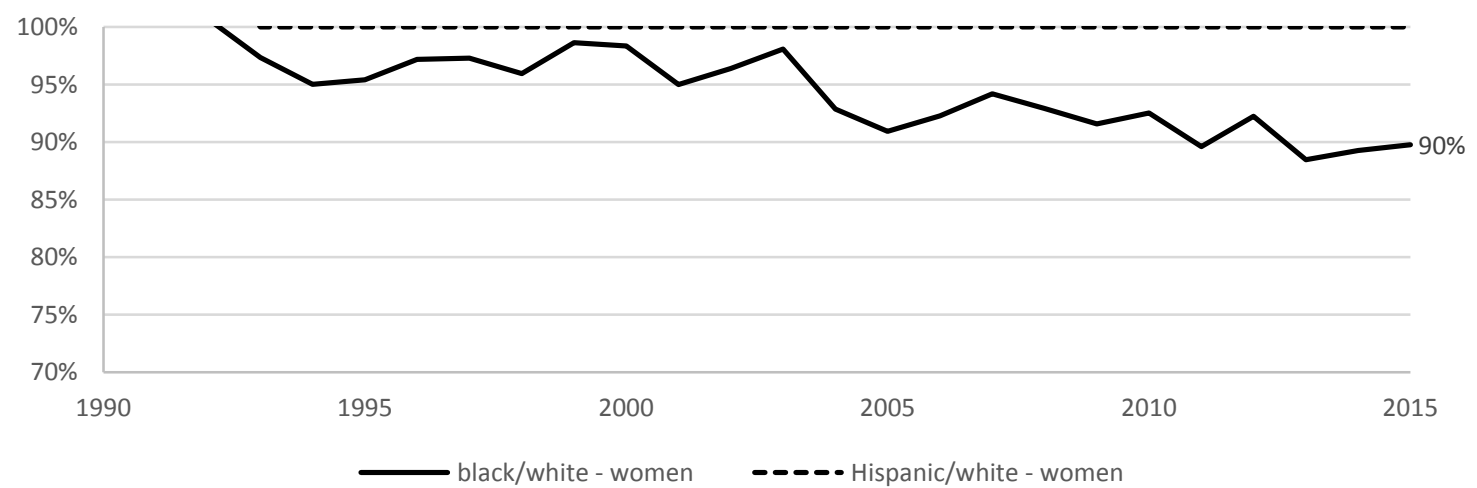

Figure 3: Women-to-men, black-to-white, and Hispanic-to-white annual health insurance costs, $1992-2015$. Notes: CPS-ASEC data on annual employer-provided health insurance (median). This includes private industry (and state and local government sector) wage and salary workers aged 18 to 65 who worked at least 20 hours per week and 26 weeks per year. 
Table 1: Women-to-men, black-to-white, and Hispanic-to-white benefit coverage ratios (percentages), 1980 and 2015.

\begin{tabular}{lcccccccc}
\hline & \multicolumn{3}{c}{ Pension coverage ratio } & \multicolumn{3}{c}{ Health insurance coverage ratio } \\
& 1980 & 2000 & 2015 & change & 1980 & 2000 & 2015 & change \\
\hline Women-to-Men & 82 & 96 & 99 & 16 & 82 & 87 & 90 & 9 \\
Black-to-White: Men & 86 & 80 & 81 & -6 & 91 & 86 & 88 & -3 \\
Hispanic-to-White: Men & 74 & 50 & 60 & -15 & 87 & 65 & 73 & -14 \\
Black-to-White: Women & 102 & 85 & 86 & -16 & 103 & 102 & 97 & -7 \\
Hispanic-to-White: Women & 85 & 66 & 67 & -18 & 96 & 80 & 80 & -16 \\
\hline
\end{tabular}

Note: Figures are for nonagricultural private sector (and state and local government sector) wage and salary workers aged 18 to 65 who worked at least 20 hours per week and 26 weeks per year.

employer's contribution to women as a percentage of the contribution to men and how much was contributed to blacks and Hispanics as a percentage of the contribution to whites. The figure shows that trends in benefit costs had similarities and dissimilarities compared with trends in benefit coverage. First, as in coverage rates, there was a slight gender convergence in the employer's contribution to health insurance: in 1992, women received about 75 cents for every dollar men received, whereas in 2015, women received 79 cents. Secondly, the gap between black and white workers in an employer's contribution to health insurance slightly increased over time parallel to the widening gap in benefit coverage. However, in contrast to what we have shown for benefit coverage, for Hispanics, benefit inequality in health insurance was almost entirely due to low levels of coverage. For workers who obtained health insurance from their employers, there was hardly any gap between Hispanic and white workers.

\section{Benefit Costs Based on the ECEC and CPS-ASEC}

Figure 3 demonstrates the importance of analyzing not only benefit coverage but also benefit costs. The latter, however, are available in the CPS only for health insurance and only since 1992. The most comprehensive data on benefits are available from the BLS-ECEC microdata on wage and benefit costs. The ECEC microdata are confidential files that are available only to BLS on-site researchers for analysis. We received permission from the BLS to analyze data of the March quarter for every year from 1982 on and to use the outputs on benefits and wages at the industry-year level outside the secure facility.

We utilized the ECEC cost-level estimates at the job level to provide a rich description of the development of voluntary benefit inequality by gender, race, and ethnicity for the lengthy period of 1982 to 2015. To address this issue, we estimated weekly benefit costs for each worker in the CPS-ASEC files by multiplying their wages (available from the CPS) by the share of wages relative to the share of voluntary benefits in the total compensation (available from our analyses of the ECEC). We did the matching according to workers' hourly wage decile in eight industrial sectors and year. The resulting data are not perfect because we used average benefit data for each wage decile in the industrial sector and assigned 
them to all CPS workers in the same wage decile and in the same industrial sector. Matching according to workers' wage decile in two-digit industries is impossible for the entire period due to the small number of observations in each detailed industry. We did it for recent years when the number of observations had significantly increased. The results (not shown) are the same. To approximate how much of the variance in benefit costs is captured in the matching procedure, we used CPSASEC individual-level data on the employer's contribution to health insurance and decomposed its variance. We found that the hourly wage decile, eight industrial sectors, and year constitute approximately 47 percent of the total variance (among workers with positive health insurance costs). ${ }^{6}$ Hence, although admittedly crude, this method enabled us to describe trends in benefit gaps by gender and race and/or ethnicity compared with well-known gender and/or racial wage gaps for 1982 to 2015.

We used CPS-ASEC data samples from 1983 to 2016 (covering earnings from 1982 to 2015). We restricted the CPS-ASEC samples to a scope that is similar to that of the ECEC by limiting it to employed nonagricultural private sector and state and local government sector workers, thereby excluding workers in agricultural industries, federal government employees, postal workers, the self-employed, and private household workers. Following the convention in inequality studies, we multiplied the top-coded wage by 1.45 and excluded those earning less than $\$ 2$ per hour in 2016 dollars.

Figure 4 presents trends in women-to-men ratios in weekly earnings, total voluntary benefits, health insurance, pension, and various types of paid leave (vacations, holidays, sick leave, etc.) for 1982 to 2015. Although women on average still earned considerably less than men, wage disparities by gender narrowed, especially during the 1980s, but remained stable through the mid-2000s (see also Blau and Kahn 2017). Since the mid-1990s, the gender gap in benefits has been somewhat smaller than the wage gap mainly due to the narrowing gender gap in costs of health insurance and paid leave. In the 1980s, 1990s, and 2000s (but not in the last two to three years), gender inequality in benefits narrowed faster than wage inequality. ${ }^{7}$ The gender gap in benefits may be even lower than our estimates because the ECEC data on benefits do not include information on the coverage and costs of parental leave. The incidence of parental leave, which 15 percent of the workforce in 2017 had access to (U.S. Department of Labor and Bureau of Labor Statistics 2017), is lumped together in the ECEC with other types of leave in a residual category called "other leave." 8

Race-more particularly, the intersection between race and gender-is of growing significance in the U.S. labor market. Since the early 1980s black-white wage inequality has widened considerably for women (Bound and Dresser 1999; Petit and Ewert 2009) and slightly for men (Mandel and Semyonov 2016; Western and Petit 2005). Not only do black workers consistently draw lower wages than white workers, racial gaps in benefit costs are higher than wage gaps (Figure 5). In 2015, black men earned about 69 cents for every dollar that white men earned but only 62 cents for every dollar that white men obtained in employer-provided benefits. For women, the figures are 79 cents and 74 cents, respectively. The gaps are highest in pension costs, lower in paid leave costs, and lowest in health insurance costs. 
a. Women-to-men - all
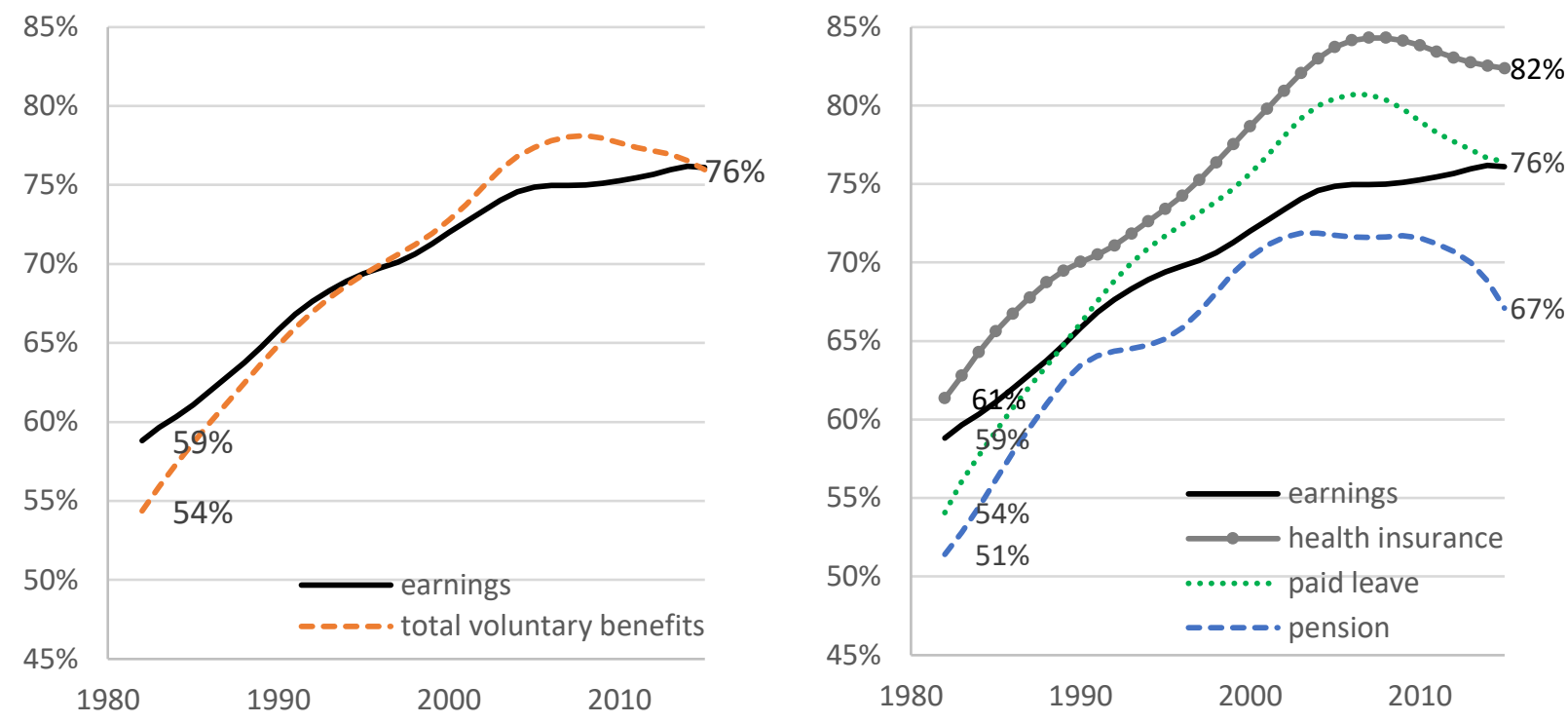

b. Women-to-men - White
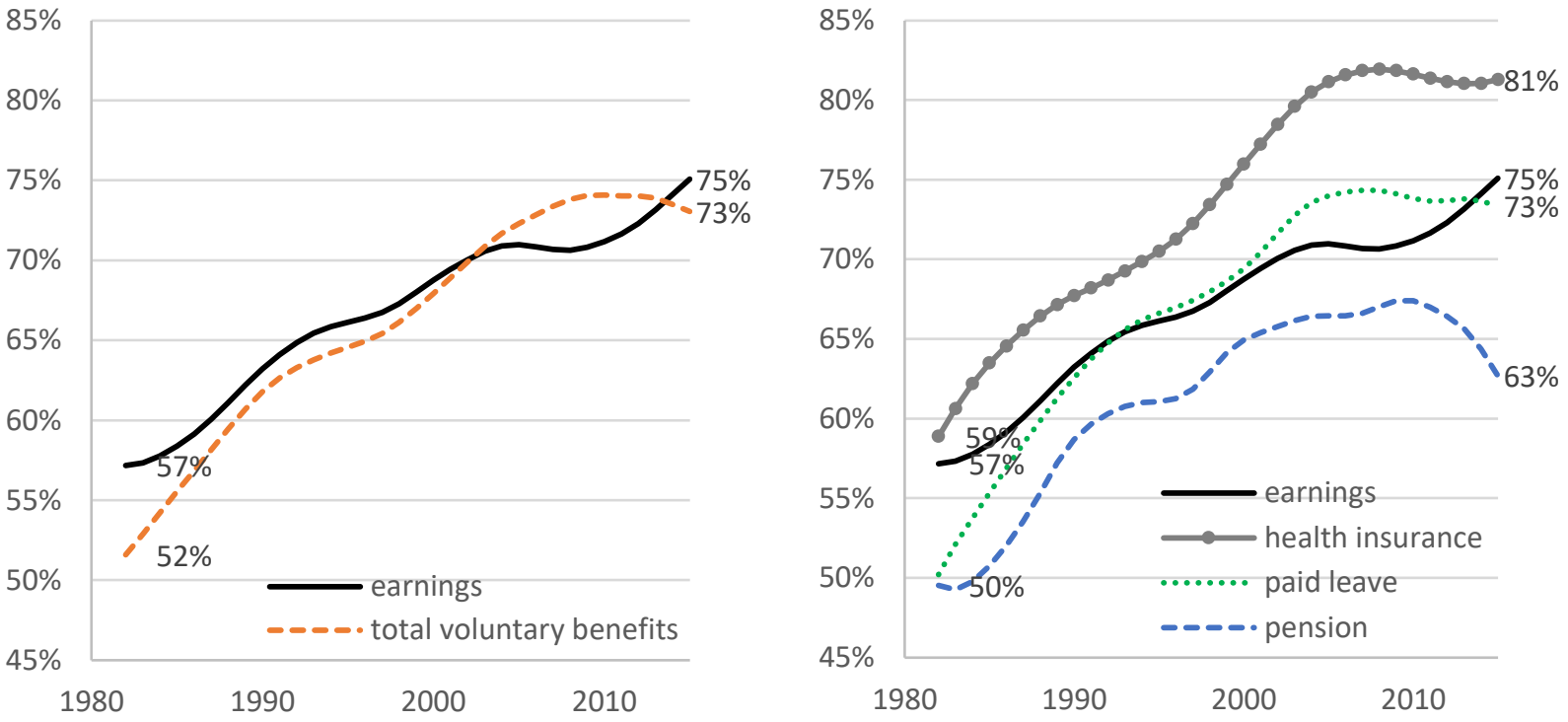

Figure 4: Women-to-men weekly health insurance, pension, paid leave, and total voluntary benefits and earnings ratios (percentages), 1982-2015. Notes: Weekly wages and weekly employer-provided benefit costs (median). This includes private industry (and state and local government sector) wage and salary workers aged 18 to 65 who worked at least 20 hours per week and 26 weeks per year. These series are smoothed by using a locally weighted regression to reduce jumpiness. Voluntary benefits include health insurance, life insurance, sickness and accident insurance, pension (defined benefit pensions and defined contribution plans), paid leave (vacations, holidays, sick leave, and other paid leave), supplemental pay (nonproduction bonuses) and other benefits (severance pay, supplemental unemployment plans, and merchandise discounts in department stores). 
Men
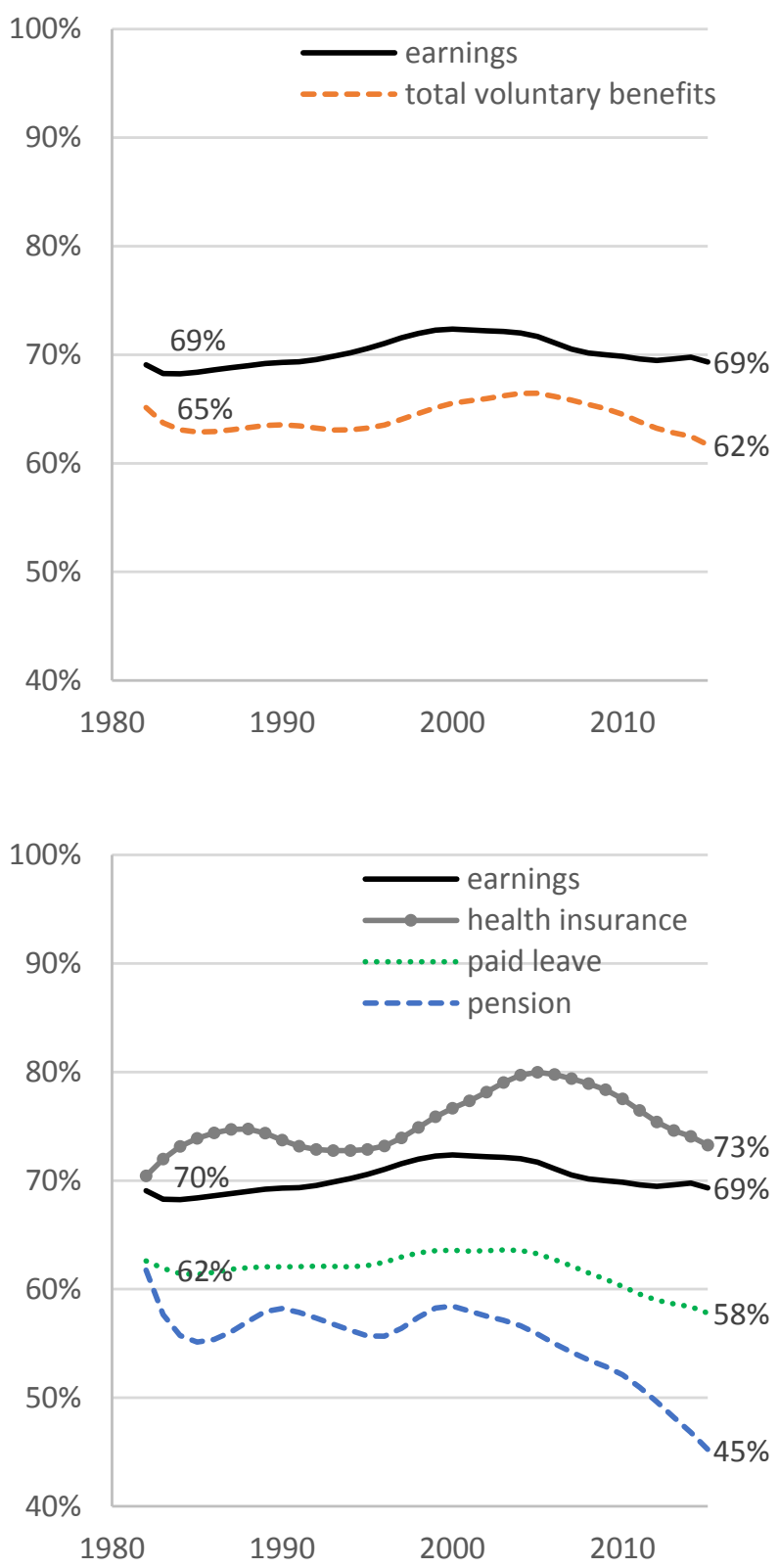

Women
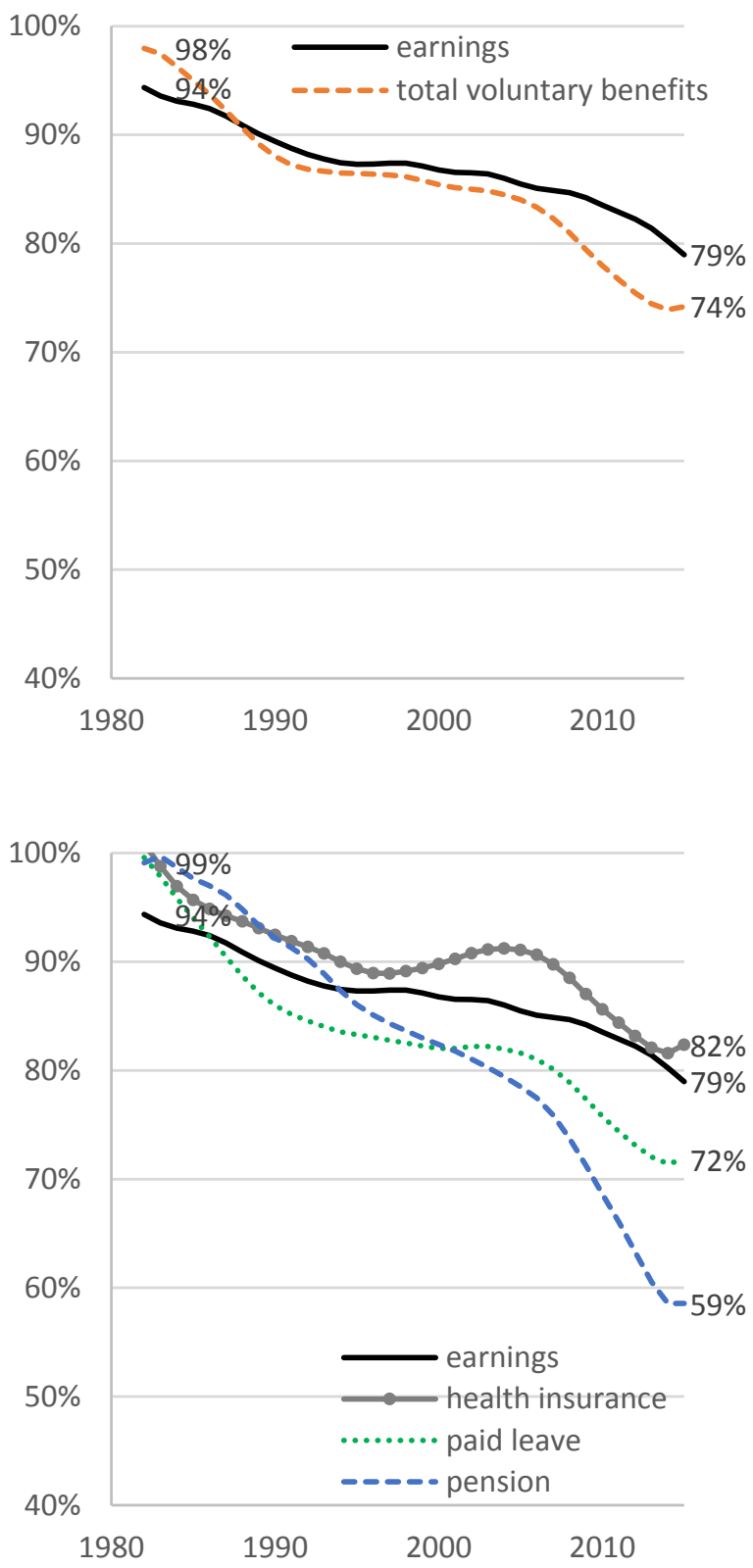

Figure 5: Black-to-white health insurance, pension, paid leave, and total voluntary benefits and earnings ratios (percentages), 1982-2015. Notes: Weekly wages and weekly employer-provided benefit costs (median). This includes private industry (and state and local government sector) wage and salary workers aged 18 to 65 who worked at least 20 hours per week and 26 weeks per year. These series are smoothed by using a locally weighted regression to reduce jumpiness. Voluntary benefits include health insurance, life insurance, sickness and accident insurance, pension (defined benefit pensions and defined contribution plans), paid leave (vacations, holidays, sick leave, and other paid leave), supplemental pay (nonproduction bonuses) and other benefits (severance pay, supplemental unemployment plans, and merchandise discounts in department stores). 
Trends over time reveal that racial inequality in benefits increased faster than wage inequality for women but only slightly more for men.

Although wage gaps between Hispanics and whites have widened over the years (particularly for women), benefit gaps have increased even more. In 2015, Hispanic men as a group earned about 63 cents for every dollar that white men earned but only 48 cents for every dollar that white men obtained in employerprovided benefits (Figure 6). The respective figures for native-born Hispanics (56 percent of Hispanics in our sample were immigrants) are 69 cents and 59 cents. For women, the gaps are somewhat lower: 69 cents and 54 cents for all Hispanic women and 75 cents and 65 cents for those who are native born. These figures suggest that most of the Hispanic disadvantage is unrelated to the migration status of more than half of the Hispanic workers. Benefit gaps between Hispanics and whites are highest in pension costs and lowest in health insurance costs. Trends over time show that ethnic inequality in benefits increased faster than wage inequality. Whereas the wage gap between Hispanic men and white men increased by six percentage points from 1982 to 2015, the benefit gap increased by 13 percentage points. For women, the wage gap increased more-by 16 percentage points—and the benefit gap increased by 24 percentage points.

Overall, we find evidence that excluding benefit costs from inequality analyses led to inaccurate conclusions regarding the size of labor market income inequality between men and women and between whites, blacks, and Hispanics and how inequalities have changed over time. Although coverage data, which are available in the CPS, intimates that racial and ethnic gaps in benefits are higher than wage gaps, we needed to analyze benefit costs to demonstrate how deep racial and ethnic inequalities really are and how much they have expanded in recent decades. Moreover, data on benefit costs were required to reveal that gender gaps in benefits are narrower and have decreased faster than wage gaps.

\section{Changes over Time in Gender, Racial, and Ethnic Income Gaps}

So far, we have presented findings that (1) the well-known racial and ethnic wage gaps underestimate overall income gaps; (2) since the mid-1990s, gender gaps in benefits have been lower than wage gaps; (3) in recent decades, benefit gaps by race (especially by ethnicity) have widened faster than wage gaps; and (4) the gender gap in benefits decreased faster than the wage gap through the 1980s, 1990s, and 2000s (but not the 2010s).

How can we explain these findings? Education and labor market disadvantages faced by black and, still more, by Hispanic workers may explain the first observation of greater benefit gaps than wage gaps. Persistent racial and ethnic wage disparities are mainly a consequence of lower levels of college enrollment and labor market variations in opportunities (Grodsky and Pager 2001; Huffman and Cohen 2004) as well as discrimination by employers and coworkers (Pager, Bonikowski, and Western 2009). Like blacks and Hispanics, women are overrepresented at the bottom of the stratification system, working in "bad" jobs that commonly offer low benefits 
Men
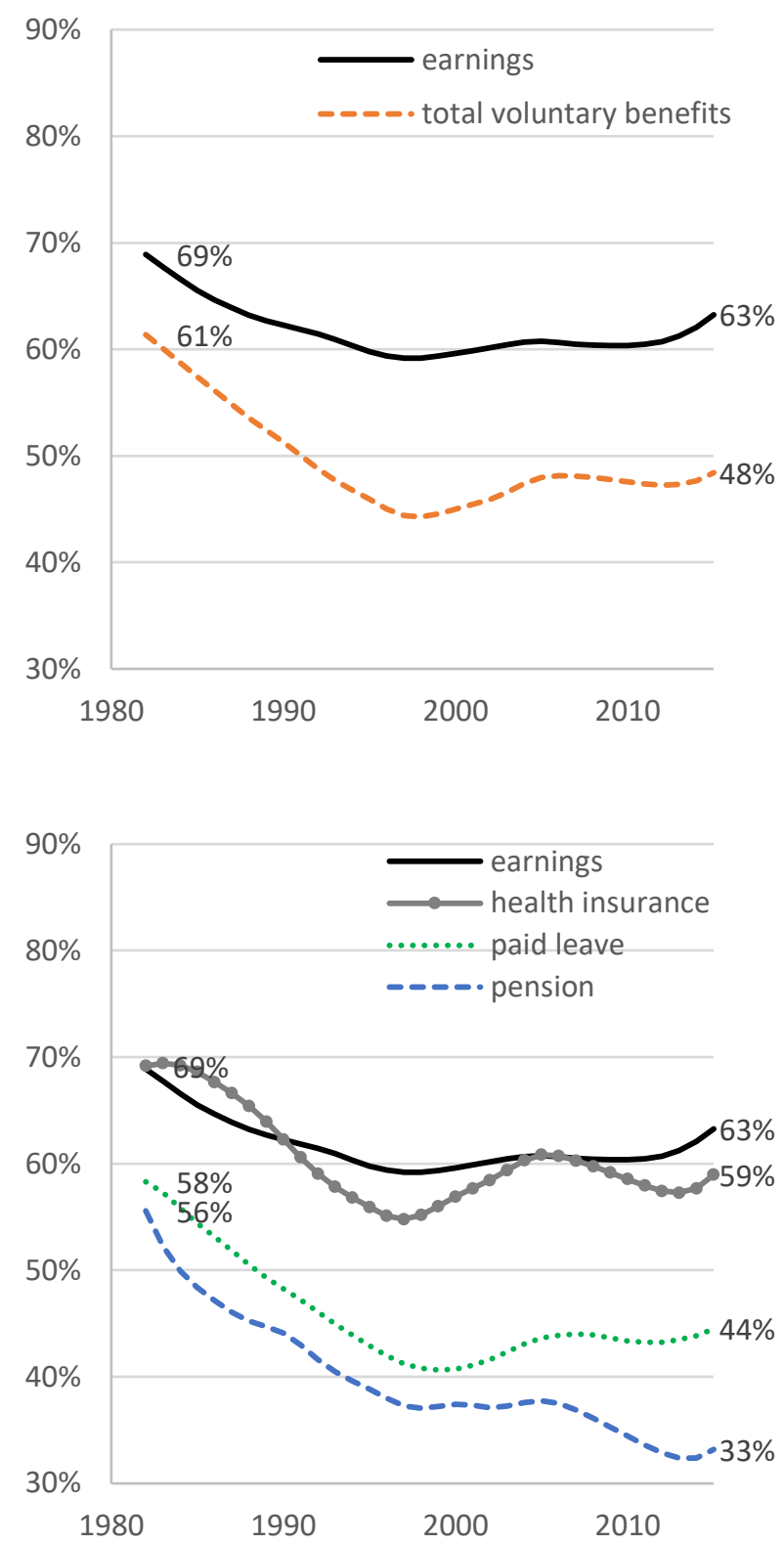

Women
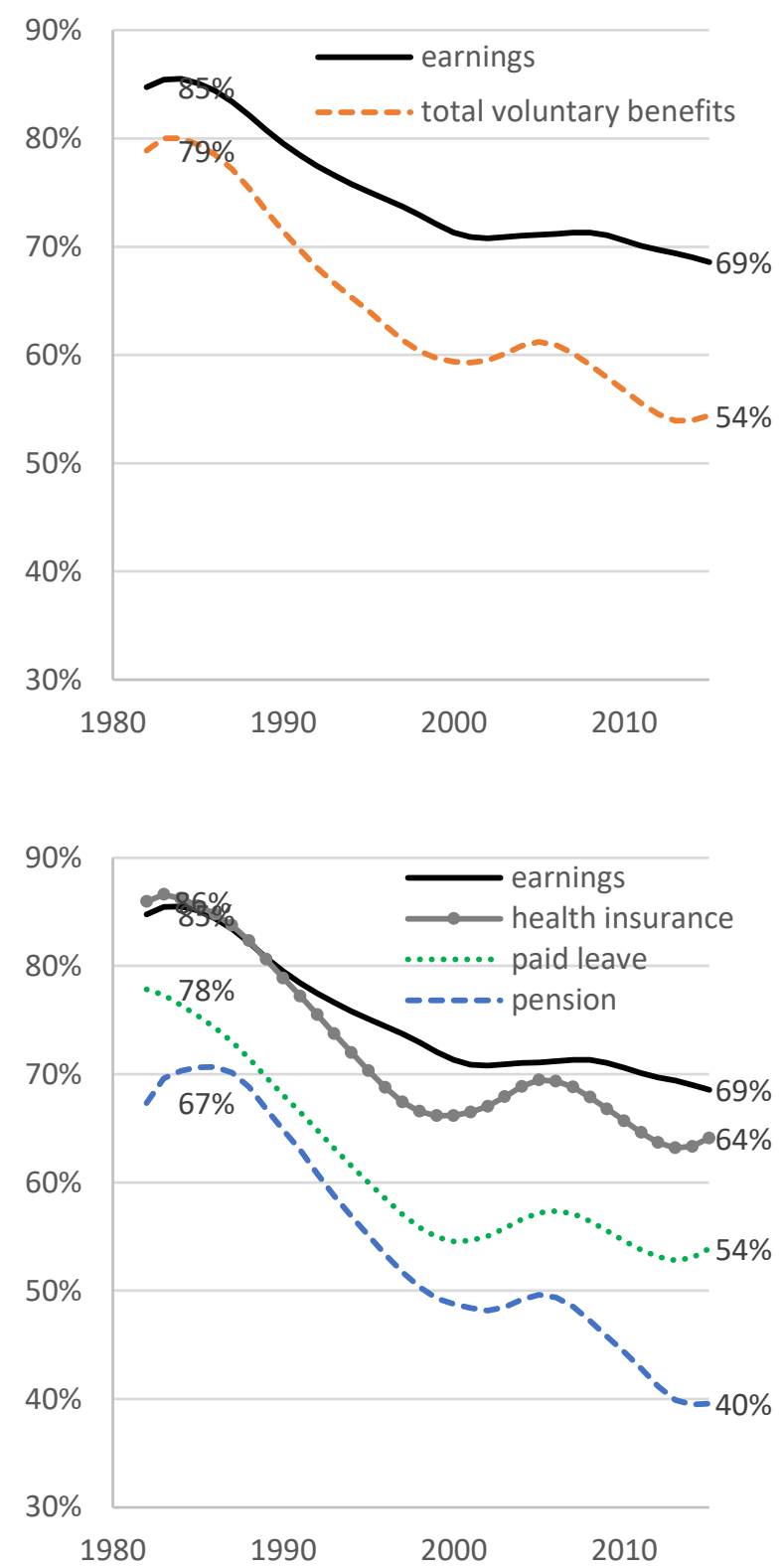

Figure 6: Hispanic-to-white health insurance, pension, paid leave, and total voluntary benefits and earnings ratios (percentages), 1982-2015. Notes: Weekly wages and weekly employer-provided benefit costs (median). This includes private industry (and state and local government sector) wage and salary workers aged 18 to 65 who worked at least 20 hours per week and 26 weeks per year. These series are smoothed by using a locally weighted regression to reduce jumpiness. Voluntary benefits include health insurance, life insurance, sickness and accident insurance, pension (defined benefit pensions and defined contribution plans), paid leave (vacations, holidays, sick leave, and other paid leave), supplemental pay (nonproduction bonuses) and other benefits (severance pay, supplemental unemployment plans, and merchandise discounts in department stores). 
(Kalleberg, Reskin, and Hudson 2000). But women are also overrepresented in the public sector and in service occupations, in which benefits are more common (Guthrie and Roth 1999; McGovern et al. 2007), which can explain why gender gaps in benefits have been lower than wage gaps (i.e., the second observation). Women may also have an unmeasured preference for benefits (Kristal 2017), as women on average have proven to be more risk-averse than men (Croson and Gneezy 2009), which could raise their relative benefits and lower their relative wages. As a result, women (but not other lower-status groups) are more likely than comparable men to receive health insurance and a pension (Averett and Hotchkiss 1995) even in the same workplace and occupation (Kristal 2017).

The above explanations for why benefit gaps are higher (racial and/or ethnic) or lower (gender) than wage gaps rest on between-group differences in wages and benefit determinants, such as education level or occupational composition, and on explanations that we cannot directly test, such as employers' discrimination and personality traits. Many studies that explain changes over time in group-based inequality commonly decompose pay gaps into these two components: changes in group-specific characteristics (e.g., occupational upgrading) and changes in unobserved gaps. These two are commonly referred to as the "explained" and "unexplained" components of the gap. The latter are often taken to be an estimate of the extent of discrimination, that is, unequal pay for equally qualified workers. The unexplained portion of the pay gap may also include the effects of unmeasured productivity or unmeasured attributes, such as noncognitive or "soft" skills, including psychological attributes, preferences, and personality, as well as the type of selection into the labor force.

Changes in group-specific characteristics are relevant for understanding the last two observations: in recent decades, benefit gaps by race, and particularly by ethnicity, widened faster than wage gaps, whereas gender gaps in benefits decreased faster than wage gaps. We expect that changes in group-specific characteristics will have a bigger impact on benefits than on wages. Some group-specific characteristics (occupations and unions in particular) should have a stronger impact on benefits than on wages, as workers in service-class occupations who exercise specialized knowledge and delegated authority are more likely to be granted benefits to ensure their long-term commitment to organizational goals and because it is cost effective for firms to invest in these workers (Goldthorpe 2000). Unions also exert a substantial positive impact on wages (Hirsch 2004) but even more so on the likelihood of union members to obtain employer-provided benefits (Budd 2007; Freeman and Medoff 1984; Rosenfeld 2014) as well as the costs of those benefits (Buchmueller, DiNardo, and Valletta 2002).

The rising level of labor market inequality since the 1980s obliges us to consider an additional important factor in explaining changes over time in group-based inequality: changes in the overall wage structure, namely, changes in returns on wage determinants, such as education and occupation. Wage structure describes the array of prices set for various labor market skills, which are rooted in innate abilities and in the particular configuration of social institutions (Weeden and Grusky 2014) and in rents (i.e., returns on an asset that are above its price) received for employment, more specifically, positions in the economy (Sørensen 2000; Wright 
1997). For example, because (on average) Hispanics have less educational attainment than whites do, an increase in the return on a college degree (as indeed has taken place since the 1980s) would cause the ethnic wage gap to widen even if Hispanics' relative education level and treatment by employers remained the same. Juhn et al. (1991) were the first to demonstrate the effect of changes in overall wage structure on group-based inequality: Between 1979 and 1987, changes in education levels and experience reduced the black-white men's wage gap, whereas changes in the returns on education and experience enlarged the gap by a similar amount. Subsequently, changes in the overall wage structure (in particular, greater returns on professional and managerial occupations, in which women were still underrepresented [Blau and Kahn 2017], and a rising payoff for long work hours in professional and managerial occupations [Cha and Weeden 2014]) were shown to explain the slowdown in the convergence of the gender gap in wages.

Changes in the group-based benefit gap should also be larger than changes in the wage gap because changes in benefit distribution were more extreme than in the wage distribution. Several recent studies demonstrate that wage inequality, which is the common measure for income inequality in the labor market, underestimates the level of compensation (i.e., wages plus costs of employer-provided benefits) inequality (Pierce 2001; Piketty et al. 2016). That changes in benefit distribution were more extreme than in wage distribution suggests that changes in returns on job characteristics were more marked for benefits than for wages, causing greater changes in the group-based benefit gap than in the wage gap.

\section{Wage Structure, Social Groups, and Benefits}

To better understand the level of and trends in benefit costs as compared with wages, we first analyze (1) the locations of the groups in the wage structure in the early 1980s, which is mainly an outcome of between-group differences in wage determinants (based on the CPS); (2) how their locations have changed in the expansion of jobs since then, which is mainly an outcome of changes in groupspecific characteristics and in the overall wage structure (based on the CPS); and (3) how benefits are distributed along the wage distribution (based on the ECEC).

Because ECEC data are at the job level, to conduct the first two analyses, we focused on job categories that are indexed by median earnings. Following Wright and Dwyer (2003), we constructed an occupation-by-industry matrix with 85 occupations and 19 industries, yielding a total of 1,615 jobs. We include in our analysis all job cells that have any people in them. We rank order these jobs from the highest median weekly earnings to the lowest and then group this rank-ordered set of cells into five ordered categories, each containing as close as possible to 20 percent of employees in the early 1980s. The bottom quintile contains roughly 20 percent of employees in 1982 to 1985 in jobs with the lowest median earnings, the top quintile contains roughly 20 percent of employees in jobs with the highest median weekly earnings, and so on. Job categories and their aggregation into quintiles were rank ordered separately for 2011 to 2015 as well.

We then used these job-quality quintiles to generate graphs showing the gender, race, and ethnicity compositions of jobs from 1983 to 1985 and the gender, race, 
and ethnicity distribution of net changes in the number of jobs in each quintile between 1983 and 1985 and between 2011 and 2015 (the value 20 denotes no change between the two periods). Figure 7 shows that in the early 1980s, women were disproportionally employed in bad jobs (56 percent of them were in the bottom two quintiles), but they improved their relative earnings in jobs created through the 1980s, 1990s, and 2000s: job expansion was highest in the fourth quintile (37 percent) and lowest in the second quintile (10 percent). In contrast to the situation of women, job expansion over recent decades reinforced racial and, more particularly, ethnic inequalities, which were already at their highest in the early 1980s. Not only were about two-thirds of Hispanic women employed in the bottom two quintiles from 1983 to 1985, but among Hispanic women who took on jobs created over the last three decades, 43 percent were in the bottom wage quintile and only 8 percent were in the top.

Women as a group were essentially "swimming upstream" in the overall wage structure in recent decades, whereas at the same time, Hispanic and black women were "swimming downstream." This may explain why the gender gap in benefits decreased faster than the wage gap and why racial and ethnic gaps in benefits increased faster than wage gaps, particularly for women. The explanation is rooted in the way benefits are distributed along the wage distribution. Figure 8 presents the real value of wages (per hour) and the ratio of voluntary benefits to wages (percentages) for the 10th, 50th, and 90th percentiles. The left-hand column of Figure 8 shows the well-known fact that wages at the lower end and middle of the distribution stagnated, whereas wages at the upper end increased. The righthand column in Figure 8 shows that voluntary benefits (mainly health insurance but others as well) increased for high-wage workers and also for median-wage workers; however, benefits for low-wage workers-among whom Hispanic and black women are overrepresented (see Figure 7)—stagnated parallel to their wages.

The low level of real benefit costs for low-wage workers-among whom, as stated, Hispanic and black women are overrepresented-is mostly the result of their low coverage rates. Figure 9 presents the percentage of workers covered by health insurance, paid leave, and pension in the 10th, 20th, 50th, and 90th percentiles in the wage distribution and the level of benefit costs for covered workers. It shows that already in the early 1980s, workers in the 10th and 20th wage percentiles had low coverage rates of health insurance, paid leave, and pension; in the following years, these rates fell even lower. For example, in the early 1980s, almost all workers were covered by paid leave. In 2015, only 65 percent of workers in the 10th wage percentile were covered by paid leave ( 24 percent by sick leave) compared with 97 percent of workers in the 90 th wage percentile ( 87 percent for sick leave). Also, almost all workers in the 90th wage percentile were covered by health insurance between 1982 and 2015, a period when health insurance costs steeply increased; but by 2015 , only 36 percent of workers in the 10th wage percentile were covered, whereas for workers in the 20th percentile, the figure was 61 percent. $^{9}$

So far, we have shown changes over time in the relative locations of groups on wage distribution and the associated benefits in each wage decile. In the next section, we use decompositions to test if indeed changes in groups' locations on the wage and benefit distributions, and changes in the overall wage and benefits structures, 


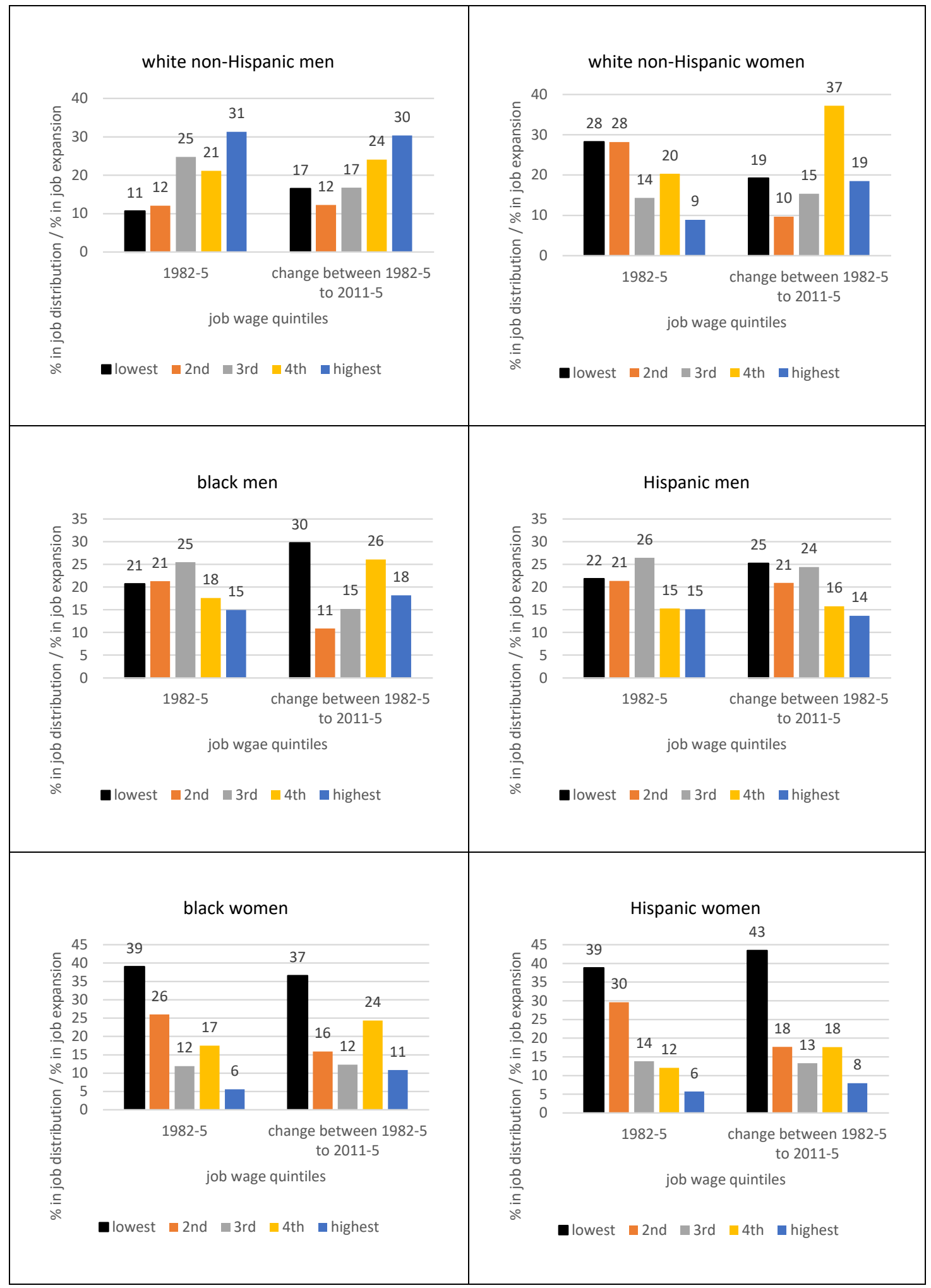

Figure 7: Job composition from 1982 to 1985 and patterns of job expansion between 1982 and 1985 and 2011 to 2015 among gender-race-ethnicity categories. Note: Private industry (and state and local government sector) wage and salary workers aged 18 to 65 who worked at least 20 hours per week and 26 weeks per year. 


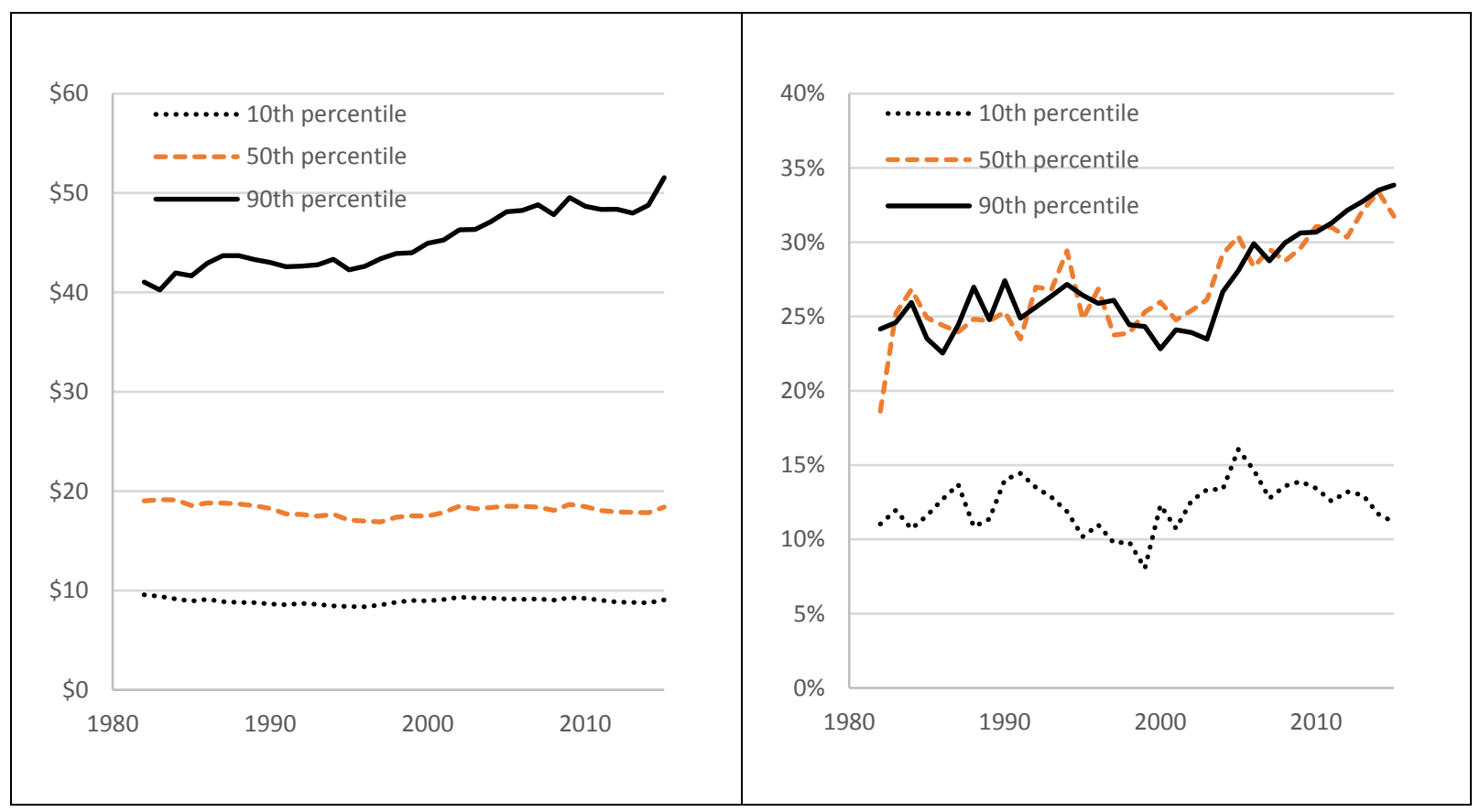

Figure 8: Wages per hour (in constant 2015 dollars) and the ratio of voluntary benefits to wages in the 10th , 50 th, and 90th wage percentiles. Note: Private industry (and state and local government sector) wage and salary workers aged 18 to 65 who worked at least 20 hours per week and 26 weeks per year.

had a greater effect on benefits than on wages, triggering more substantial changes in gender, racial, and ethnic benefit gaps than in wage gaps.

\section{Decomposition of Wage and Benefits Gaps}

The structural and institutional changes outlined in the section on changes over time in gender, racial, and ethnic income gaps are most likely responsible for changes observed in the relative location of women and minorities on the wage and benefit distributions presented in the section on wage structure, social groups, and benefits. To estimate the specific factors that explain benefit gaps by gender, race, and ethnicity compared with wage gaps and changes over time, we follow Juhn et al. (1991) (see also Blau and Kahn 1997) and decompose the 1982-to-2015 difference in gender, racial, and ethnic income gaps into a portion based on group-specific factors and a portion based on changes in the overall level of income inequality.

The following equations illustrate decomposition for gender. For year $t$, we estimated separate men $(m)$ and women $(f)$ ordinary least squares (OLS) wage regressions for individual $i$ :

$$
\begin{aligned}
& Y_{m}=X_{m} B_{m}+u_{m} \\
& Y_{f}=X_{f} B_{f}+u_{f},
\end{aligned}
$$




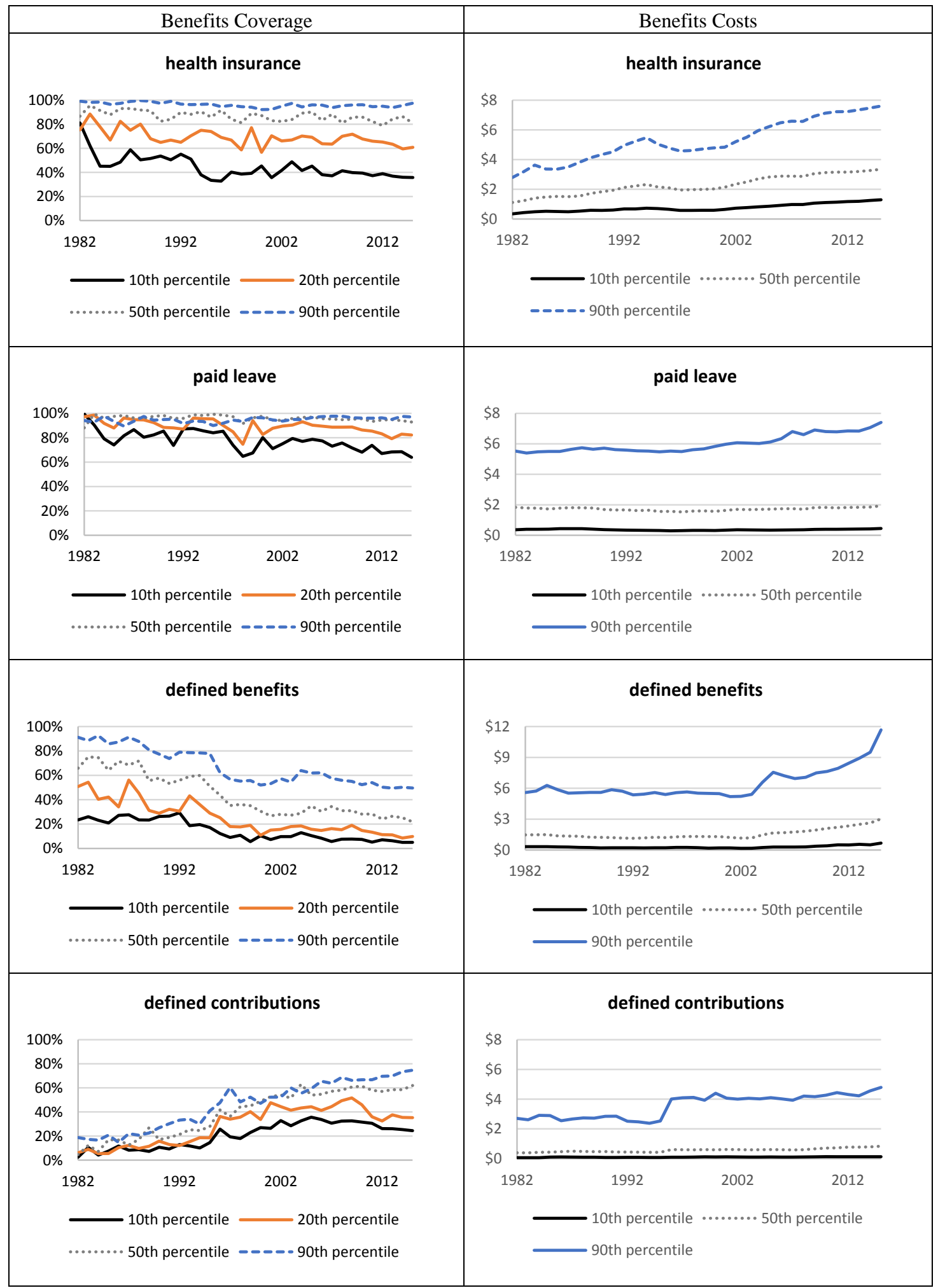

Figure 9: Benefits coverage (fraction of jobs with positive employer costs) according to wage percentiles and benefits costs (for covered workers). Note: Private industry (and state and local government sector) wage and salary workers aged 18 to 65 who worked at least 20 hours per week and 26 weeks per year. 
where $Y$ is the log of wages (benefits), $X$ is a vector of explanatory variables (such as education and occupation), $B$ is a vector of coefficients, and $u$ is an error term. We then decomposed gender-racial-ethnic income gaps between two time points, denoted by 0 and 1 , into three components:

$$
\begin{gathered}
\text { effect of changing means }=\left(\Delta \bar{X}_{1}-\Delta \bar{X}_{0}\right) b_{1 m^{\prime}} \\
\text { effect of changing coefficients }=\Delta \bar{X}_{0}\left(b_{1 m}-b_{0 m}\right) \text {, and }
\end{gathered}
$$

effect of changing unexplained gaps $=\bar{X}_{1 f}\left(b_{1 m}-b_{1 f}\right)-\bar{X}_{0 f}\left(b_{0 m}-b_{0 f}\right)$,

where $X$ and $b$ were defined previously and a $\Delta$ prefix signifies the (mean) menwomen, white-black, and white-Hispanic difference for the variable immediately following. The effect of changing means is that it measures the contribution of changes in men-women, white-black, and/or white-Hispanic differences in the measured characteristics ( $\left.X^{\prime} \mathrm{s}\right)$ to changes in the gender-racial-ethnic income gap. For example, if women move into higher-paying occupations, this will reduce the gender wage gap. The effect of changing coefficients reflects the impact of changes in prices of measured characteristics, as indexed by men-white coefficients, on changes in the gender-racial-ethnic income gap. ${ }^{10}$ For example, a rise in the return on occupations in which men are more heavily represented weights the gender difference in occupations more heavily, hence raising the gender wage gap, everything else being equal. Finally, the effect of changing unexplained gaps is to measure the impact of this factor on changes in the gender-racial-ethnic wage gap with, for example, an enlarged, unexplained gap acting to enlarge the ethnic wage gap. The latter is often taken to be an estimate of the extent of discrimination-that is, unequal pay for equally qualified workers. However, the unexplained portion of the pay gap may include the effects of unmeasured productivity-related attributes. The cumulative impact of changing means, changing coefficients, and changes in the unexplained gap equals the observed change in the total wage gap.

The decomposition of benefits and wage gaps is based on CPS-ASEC data matched to ECEC data according to workers' hourly wage decile, industrial sector, and year. We decomposed the 1982-to-2015 differences in the gender, racial, and ethnic income gaps by estimating models for a pooled sample of the years 1982 to 1985 and a pooled sample of the years 2012 to 2015 in order to get a large enough number of observations (therefore, models also include four-year dummies). Our analyses include the variables traditionally utilized in models for predicting earnings and benefits: education level (four ordinal categories: less than high school, high school graduate, some college, and college graduate [the omitted category]), potential years of work experience (i.e., age and years of schooling [6]) and its squared term, race and/or ethnicity (black, Hispanic, other, and white [the omitted category]), ${ }^{11}$ marital status (married $=1$ ), number of children, presence of a child under age 5 (yes $=1$ ), region (Midwest, South, West, and Northeast [the omitted category]), metropolitan area (yes $=1$ ), weekly working hours, occupation (two 
digits according to 1990s coding), ${ }^{12}$ and sector (state or local government $=1$ ). There are no data on union membership in the CPS-ASEC files. To estimate union effects on benefit and wage gaps (for unionized and nonunionized workers), we replicated the methodological strategy employed by Western and Rosenfeld (2011) and by Rosenfeld (2014) by measuring industry-region unionization rates based on CPS-MORG data. We followed their strategy and classified workers into 18 industries and four regions, which yielded 72 industry regions per year. ${ }^{13}$

Table 2 shows the decomposition of the closing of the men-women pay gap into gender-specific and wage-structure effects. The wage gap narrowed by 0.1976 $\log$ points over the period, and the benefit gap narrowed by $0.2809 \log$ points. Under the "Observed X's" heading, the row for "All X's" indicates that women's improved levels of the explanatory variables were sufficient to account for 57.4 percent $(0.1135$ and 0.1976$)$ of the wage convergence and for 66.3 percent $(0.1862$ and 0.2809 ) of the benefit convergence. Disaggregating by type of variable, we find that women's rising relative education levels and shifts in occupations and men's declining unionization rates were sufficient to account for most of the "All $\mathrm{X}^{\prime} \mathrm{s}$ " effect, 39.8 percent of the overall convergence in the gender wage gap, and 50.3 percent of the overall convergence in the gender benefit gap. These results for the wage gap are consistent with those of previous research (Blau and Kahn 2017; DiPrete and Buchmann 2013). For benefits, they suggest that changes in the locations of men and women in the income distribution affected the benefit gap more than the wage gap, causing closer convergence in benefits than in wages.

For the period of 1982 to 2015, price changes were not found to play a major role in the overall convergence in the gender wage or benefit gaps, whereas the decline in the unexplained gender income gaps substantially accounted for the wage and benefit convergence of women and men, explaining nearly half of the closing gaps ( 0.0978 and 0.1976 for wages, respectively, and 0.1353 and 0.2809 for benefits, respectively). Considering the greater effect of the changing unexplained gap in benefits, this may be the result of greater changes in women's tastes regarding benefits. Desegregation at the workplace level (Tomaskovic-Devey et al. 2006), which is commonly unobserved in income surveys, may also account for benefits more than wages, as nondiscrimination rules in the U.S. federal tax code limit within-firm inequality in the provision of nonwage benefits (Carrington, McCue, and Pierce 2002).

Table 2 also shows the decomposition of growth in the ethnic pay gap into ethnicity-specific and wage-structure effects. For men and women alike, the wage gap widened over the period (by $0.1023 \log$ points for men and by $0.1938 \log$ points for women), but the benefit gap widened even more (by 0.1847 and $0.3334 \log$ points, respectively). Ethnicity pay gaps widened mainly due to Hispanics' poorer (relative) levels on the explanatory variables. Lower levels of education and work experience as well as occupational composition (Duncan, Hotz, and Trejo 2006) negatively affected wages and benefits for Hispanic workers, accounting for most of the rising wage and benefits gaps. Akin to the findings for gender, ethnicity-based differences in education, work experience, and occupation had a greater effect on benefits than on wages. In addition, changes in the wage and benefit structures-changing prices for education, occupation, and working hours-had a greater effect on benefits. The 


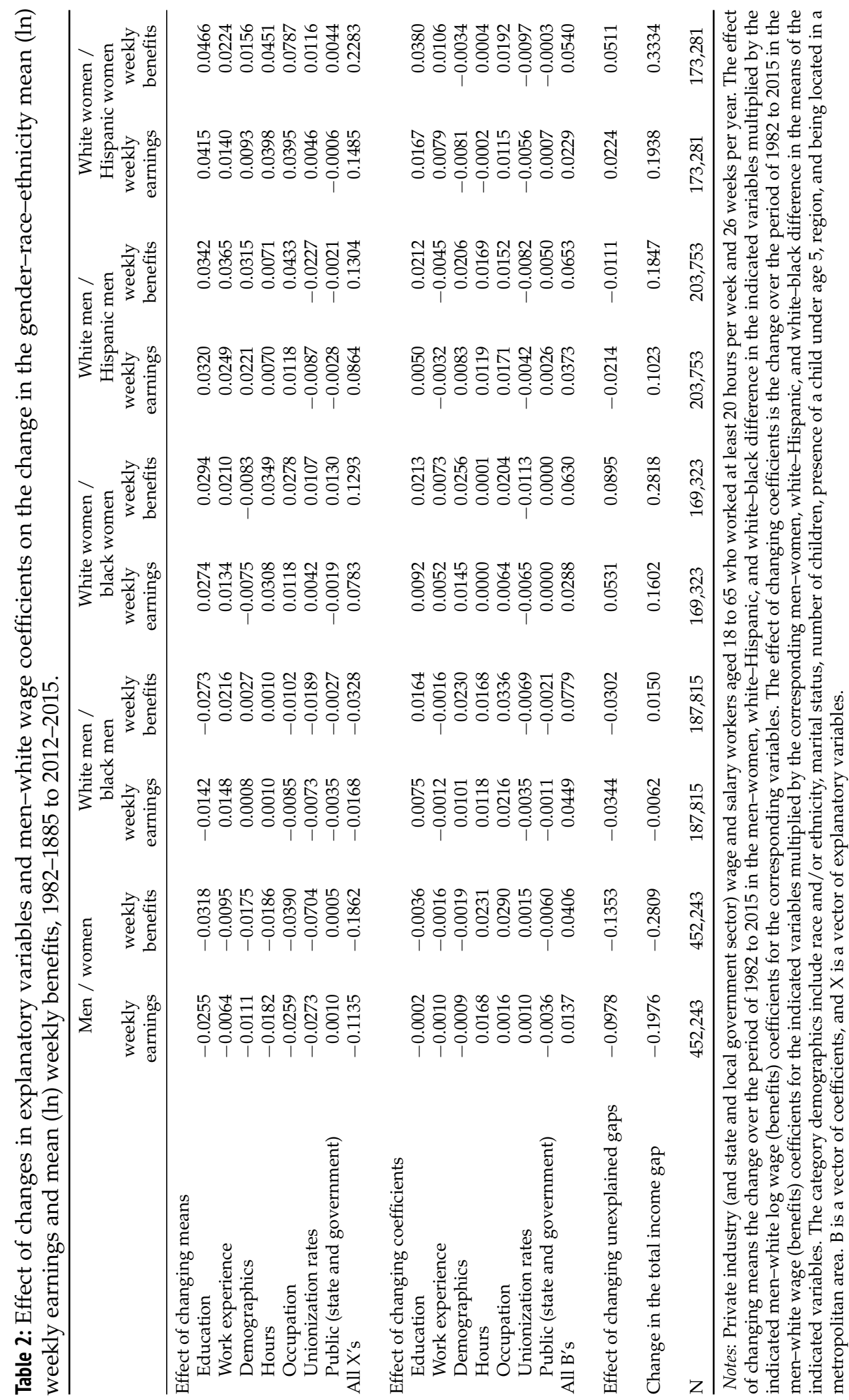


higher price for education widened the benefit gap between white and Hispanic men by $0.0212 \log$ points compared with only $0.0050 \log$ points in wages. Because data on whether persons were born in the United States are available in the CPS only from 1993, the models did not include a variable for being an immigrant.

The black-white wage gap for men hardly changed, but the benefit gap widened slightly, mainly due to changes in returns on education and occupational composition, which were larger for benefits than for wages. For women, the wage gap widened over the period by 0.1602 log points, but the benefit gap widened even more, by $0.2818 \log$ points. This was due to a sharper decline in the location of black women on the benefit distribution than on the wage distribution and changes in the overall wage and benefit structure. Specifically, the steeper decline in unionization rates for black women compared with white women, as well as rising returns on education and occupation (Dozier 2010), led to a greater increase in the benefit gap than in the wage gap.

The above decompositions underline the specific factors that explain the descent of blacks and Hispanics and the ascent of women on the wage distribution. These changes affected benefits more than wages, resulting in a greater convergence in benefits than in wages for women but a greater increase in benefits than in wages for ethnic and/or racial minority groups.

\section{Discussion and Conclusions}

Overall, we have presented evidence that excluding benefits from inequality analyses has led to an overestimate of the size of labor market income inequality between men and women and to an underestimate of the inequality levels between whites and blacks and between whites and Hispanics. Furthermore, over the years, benefit gaps by race (particularly by ethnicity) widened faster than wage gaps, whereas the reverse was the case with the gender gap: until 2010, the benefit gap between men and women decreased faster than the wage gap.

How can we explain these findings? The answer seems rooted in the types of jobs the various groups (men, women, blacks, and Hispanics) hold. Blacks and Hispanics are overrepresented at the bottom of the wage distribution, working in "bad" jobs that commonly offer low benefits, which explains their dire situation in that area. Women are also overrepresented at the bottom of the wage distribution, but unlike blacks and Hispanics, they are also overrepresented in what Goldthorpe (2000) calls "service relations," or occupations in which benefits are common, as they are viewed as the means whereby employers create and sustain workers' commitment to and cooperation in their organizational goals.

Changes over time in the types of jobs held by women, blacks, and Hispanics help explain the growing racial and ethnic gaps in benefits as well as the declining gender gap in them. Specifically, between 1982 and 2015, women increased their representation in "good" jobs in the second quintile of the earnings distribution, which tends to provide good benefits, whereas in the same period, blacks and Hispanics increased their representation in "bad" jobs located at the bottom of the earnings distributions, which tend to provide few benefits or none. Results from the decomposition suggest that women's rising education levels and shifts in 
occupations and men's falling unionization rates affect the benefit gap more than the wage gap, causing greater convergence in benefits than in wages. By contrast, Hispanic and black women's declining relative education levels and occupational mix have a greater effect on the benefit gap than on the wage gap, causing greater enlargement of the former than the latter.

Moreover, in recent decades, benefits stagnated at the bottom of the distribution but not at the median or the top, thereby widening the ethnic and racial gaps in benefit inequality more than in wage inequality. This occurred, we suspect, mainly due to the relative rigidity of wages compared with benefits at the bottom of the wage and job distributions, where blacks and Hispanics were overrepresented. "Downward wage rigidity," "wage stickiness," or simply "wage rigidity" are terms used to refer to the well-known fact that nominal wages rarely fall (Bewley 1999). Benefits, however, appear to be more flexible than wages. Previous research (Babecký et al. 2012; Lebow, Saks, and Wilson 2003) demonstrates that total compensation costs evince less rigidity than do wage costs alone, suggesting that firms are able to circumvent wage rigidity in part by varying benefits. Because wage cuts have a detrimental impact on workplaces, employers may prefer to cut benefits rather than wages. It is also more practical to cut benefits rather than wages for low-wage workers for the obvious reason that firms cannot cut wages below the minimum.

But there is a difference between workers located at the top and middle of the wage distribution (where many women are located) and low-wage workers (where most black women and Hispanics, men and women, are located). Some lowearning workers may perceive a cut in benefits as unfair, but their need for cash for everyday life induces them to view payments in kind or deferred compensation as less essential than cash in hand. Moreover, because financial literacy is particularly low in workers who are more likely to earn low wages-people who are young, less educated, women, Hispanic, and black (Lusardi and Mitchell 2014)—they are less likely to plan well for retirement and therefore may view employer-provided benefits as less important than wages without being fully aware of the consequences. High- and middle-earning workers, however, are more financially literate, less in need of cash, and may even prefer deferred compensation for tax reasons.

Therefore, low-wage workers are less likely to profit from downward benefit rigidity than from downward wage rigidity, at least in terms of coverage. Nonstandard employment relations, which have expanded since the 1980s, provide employers with a legal basis to cut benefit coverage for flexible staffers, including the use of service contractors, part-time workers, and workers with fewer than three years of service (Kalleberg, Reynolds, and Marsden 2003); most of these are located at the bottom of the wage distribution. Although it is illegal for employers to discriminate between high- and low-wage workers in benefit levels, there are legal ways to lower benefit costs for low-wage workers while raising them for middleand high-wage workers. Offering different health benefit options with different levels of employee contributions or pension contributions, which are dependent on employee matching, are two such methods. No data are available regarding this point; nevertheless, low-wage workers (including a disproportionate number of Hispanics and blacks), lacking financial means and knowledge, are likely to choose low-cost benefits with minimal or no employee contribution, whereas middle- and 
high-wage workers (including a disproportionate number of white women) will normally choose the high-cost health and pension options, thereby producing the main results obtained in this article: a steeper increase in racial and ethnic benefit inequality than in wage inequality and a faster decrease in gender wage inequality than in benefit inequality.

\section{Notes}

1 Mandatory (legally required) benefits accounted for 7.5 percent of total employer compensation costs in 2015.

2 Excluding workers who worked fewer than 20 hours per week (about 3.3 percent of the study's population) leads to a conservative estimate of gender differences in benefits. Among workers who were employed for fewer than 20 hours per week, women were overrepresented but not black or Hispanic workers (who are overrepresented among workers who are employed between 20 to 35 hours per week). In terms of coverage, restricting the sample to workers who put in 20 hours per week or more reduces gender gaps only by 1 percentage point and only in the 1980s. In terms of costs, this restriction reduces gender wage and benefit gaps by about 2 percentage points consistently over the years but does not affect racial and ethnic differences in benefits. The effects on the gender gap are small because part-time work among men increased mostly among those working 20 to 35 hours per week (from 4.2 percent in 1980 to 7.2 percent in 2015), whereas the rise among men working fewer than 20 hours has hardly changed (increased from 1.5 percent in 1980 to 1.7 percent in 2015).

3 Exclusion of federal government employees may lead to an underestimation of the gender gap in benefits and to an overestimation of the racial gap because federal employees differ somewhat from state and local employees in the distribution of gender and race groups (Hispanic employees are generally underrepresented in all branches of government). The majority of federal government employees are men, whereas the majority of state and local government employees are women. Quite the reverse is the situation for black workers, men and women alike, who are overrepresented in federal government even more than in state and local government. But having acknowledged these potential differences, it is important to note that the federal workforce is a very small proportion of the workforce. An approximate 2 to 3 percent of the workforce is employed by the federal government, which is less than in both state ( 5 to 6 percent) and local (8 to 9 percent) government. Indeed, when including federal government employees in analyses of pension and health insurance coverage, we got very similar results.

4 When coverage as a dependent rather than as a policyholder is taken into account, women are more likely than men to be covered by health insurance (Levy 2006).

5 The CPS estimates of employer contributions to health insurance were obtained by matching data from the 1977 National Medical Care Expenditures Survey (NCMES) according to (1) type of plan, (2) proportion of cost paid by employer, (3) level of earnings, (4) type of worker (part-time or full-time), (5) industry, (6) occupation, (7) sector (private or government), (8) region, (9) residence, and (10) personal characteristics, such as age, race, marital status, and education.

6 Adding one-digit occupation (ECEC data include information on one-digit codes for 1982 to 1995, three-digit codes for 1996 to 2003, and six-digit codes from 2004 onward), we 
found that hourly wage decile, eight industrial sectors, year, and occupation constituted approximately 48 percent of the total variance.

7 Data on health insurance are present in our data and in the CPS-ASEC data, so they can be compared; overall, the trend is very similar. But the ECEC-based data reveal a steeper trend (from 71 percent in 1992 to 82 percent in 2015 compared with 75 percent to 79 percent, respectively).

8 The cost estimate of this residual category (5 percent of the total cost of paid leave) does not include parental leave.

9 Because the ECEC unit of observation is a job within an establishment, these measures are conceptually closer to an employer's pension offer rate and a health insurance offer rate, whereas the coverage rates based on the CPS data represent a take-up rate.

10 Because there are differential effects of children on fathers and mothers in the household, we estimated Juhn et al.'s (1991) decompositions of the closing of the men-women income gap by also using women's wage-benefit coefficients. The main result-that changes in the locations of men and women in the income distribution (due to women's rising relative education levels, shifts in occupations, and men's declining unionization rates) affected the benefit gap more than the wage gap, causing closer convergence in benefits than in wages-did not change (results not shown).

11 Because the analysis focused on comparisons of blacks and whites and of Hispanics and whites, we excluded from the relevant analysis all other racial and/or ethnic groups (e.g., Hispanics were excluded from the black-white analysis).

12 The two-digit classification provides about 80 occupational categories that are comparable across decades.

13 Jake Rosenfeld kindly shared his industry codes with us.

\section{References}

Averett, Susan, and Julie Hotchkiss. 1995. "The Probability of Receiving Benefits at Different Hours of Work." American Economic Review 85:276-80.

Babecký Jan, Philip Du Caju, Theodora Kosma, Martina Lawless, Julian Messina, and Tairi Rõõm. 2012. "How Do European Firms Adjust Their Labour Costs When Nominal Wages Are Rigid?" Labour Economics 19:792-801. https://doi.org/10.1016/j . labeco. 2012. 03.010.

Bewley, Truman. 1999. Why Wages Don't Fall During a Recession. Cambridge, MA: Harvard University Press.

Blau, Francine, and Lawrence Kahn. 1997. "Swimming Upstream: Trends in the Gender Wage Differential in the 1980s." Journal of Labor Economics 15:1-42. https ://doi .org/10. $1086 / 209845$.

Blau, Francine, and Lawrence Kahn. 2017. “The Gender Wage Gap: Extent, Trends, and Explanations." Journal of Economic Literature 55:789-865. https ://doi .org/10.1257/jel. 20160995.

Bound, John, and Laura Dresser. 1999. "Losing Ground: The Erosion of the Relative Earnings of African American Women During the 1980s." Pp. 61-104 in Latinas and African American Women at Work, edited by I. Browne. New York, NY: Russell Sage Foundation.

Buchmueller, Thomas, John Dinardo, and Robert Valletta. 2002. “Union Effects on Health Insurance Provision and Coverage in the United States." Industrial and Labor Relations Review 55:610-27. https://doi.org/10.1177/001979390205500403. 
Budd, John. 2007. "The Effect of Unions on Employee Benefits and Non-Wage Compensation: Monopoly Power, Collective Voice, and Facilitation." Pp. 160-92 in What Do Unions Do? A Twenty-Year Perspective, edited by J. T. Bennett and B. E. Kaufman. New Brunswick, NJ: Transaction Publishers.

Burkhauser, Richard, and Kosali Simon. 2010. Measuring the Impact of Health Insurance on Levels and Trends in Inequality. Working paper, National Bureau of Economic Research.

Carrington, William, Kristin McCue, and Brooks Pierce. 2002. "Nondiscrimination Rules and the Distribution of Fringe Benefits." Journal of Labor Economics 20:S5-S33. https: //doi.org/10.1086/338672.

Cha, Youngjoo, and Kim Weeden. 2014. "Overwork and the Slow Convergence in the Gender Gap in Wages." American Sociological Review 79:457-84. https://doi.org/10. $1177 / 0003122414528936$.

Chung, Wankyo. 2003. "Fringe Benefits and Inequality in the Labor Market." Economic Inquiry 41:517-29. https://doi .org/10.1093/ei/cbg025.

Croson, Rachel, and Uri Gneezy. 2009. "Gender Differences in Preferences." Journal of Economic Literature 47:1-27. https ://doi.org/10.1257/jel.47.2.448.

DiPrete, Thomas, and Claudia Buchmann. 2013. The Rise of Women: The Growing Gender Gap in Education and What It Means for American Schools. New York, NY: Russell Sage Foundation.

Dozier, Raine. 2010. “The Declining Relative Status of Black Women Workers, 1980-2002." Social Forces 88:1833-58. https://doi.org/10.1353/sof .2010.0022.

Duncan, Brian, Joseph Hotz, and Stephen Trejo. 2006. "Hispanics in the U.S. Labor Market." Pp. 228-90 in Hispanics and the Future of America, edited by M. Tienda and F. Mitchell. Washington, DC: National Academies Press.

Freeman, Richard, and James Medoff. 1984. What Do Unions Do? New York, NY: Basic Books.

Goldthorpe, John. 2000. On Sociology: Numbers, Narratives, and the Integration of Research and Theory. Oxford, UK: Oxford University Press.

Grodsky, Eric, and Devah Pager. 2001. "The Structure of Disadvantage: Individual and Occupational Determinants of the Black-White Wage Gap." American Sociological Review 66:542-67. https://doi.org/10.2307/3088922.

Guthrie, Doug, and Louise Marie Roth. 1999. "The State, Courts, and Maternity Policies in U.S. Organizations: Specifying Institutional Mechanisms." American Sociological Review 64:41-63. https://doi.org/10.2307/2657277.

Haberfeld, Yitchak, and Yinon Cohen. 2007. "Gender, Ethnic, and National Earnings Gaps in Israel: The Role of Rising Inequality." Social Science Research 36:654-72. https ://doi . org/10.1016/j.ssresearch.2006.02.001.

Hersch, Joni, and Shelly White-Means. 1993. "Employer-Sponsored Health and Pension Benefits and the Gender/Race Wage Gaps." Social Science Quarterly 74:851-66.

Hirsch, Barry. 2004. "Reconsidering Union Wage Effects: Surveying New Evidence on an Old Topic." Journal of Labor Research 25:233-66. https://doi.org/10.1007/ s12122-004-1035-4.

Huffman, Matt, and Philip Cohen. 2004. "Racial Wage Inequality: Job Segregation and Devaluation across U.S. Labor Markets." American Journal of Sociology 109:902-36. https : //doi.org/10.1086/378928.

Juhn, Chihui, Kevin Murphy, and Brooks Pierce. 1991. "Accounting for the Slowdown in Black-White Wage Convergence." Pp. 107-43 in Workers and Their Wages, edited by M. Kosters. Washington, DC: AEI Press. 
Kalleberg, Arne, Barbara Reskin, and Ken Hudson. 2000. "Bad Jobs in America: Standard and Nonstandard Employment Relations and Job Quality in the United States." American Sociological Review 65:256-78. https://doi .org/10.2307/2657440.

Kalleberg, Arne, Jeremy Reynolds, and Peter Marsden. 2003. "Externalizing Employment: Flexible Staffing Arrangements in US Organizations." Social Science Research 32:525-52. https://doi.org/10.1016/S0049-089X (03)00013-9.

Kristal, Tali 2017. “Who Gets and Who Gives Employer-Provided Benefits: Evidence from Matched Employer-Employee Data." Social Forces 96:31-64. https : //doi .org/10 . 1093/ sf/sox048.

Lebow, David, Raven Saks, and Beth Wilson. 2003. "Downward Nominal Wage Rigidity: Evidence from the Employment Cost Index." Advances in Macroeconomics 3(1):1117. https://doi.org/10.2202/1534-6013.1117.

Levy, Helen. 2006. "Health Insurance and the Wage Gap." Working paper, National Bureau of Economic Research.

Lusardi, Annamaria, and Olivia Mitchell. 2014. "The Economic Importance of Financial Literacy: Theory and Evidence." Journal of Economic Literature 52:5-44. https://doi. org/10.1257/jel.52.1.5.

Mandel, Hadas, and Moshe Semyonov. 2016. “Going Back in Time? Gender Differences in Trends and Sources of the Racial Pay Gap, 1970 to 2010." American Sociological Review 81:1039-68. https://doi.org/10.1177/0003122416662958.

McGovern Patrick, Stephen Hill, Colin Mills, and Michael White. 2007. Market, Class, and Employment. Oxford, UK: Oxford University Press. https : //doi.org/10.1093/acprof : oso/9780199213375.001.0001.

Mishel, Lawrence, Josh Bivens, Elise Gould, and Heidi Shierholz. 2012. The State of Working America. 12th ed. Ithaca, NY: ILR Press.

Pager, Devah, Bart Bonikowski, and Bruce Western. 2009. "Discrimination in a Low-Wage Labor Market: A Field Experiment." American Sociological Review 74:777-99. https: //doi.org/10.1177/000312240907400505.

Petit, Becky, and Stephanie Ewert. 2009. “Employment Gains and Wage Declines: The Erosion of Black Women's Relative Wages Since 1980." Demography 46:469-92. https : //doi.org/10.1353/dem.0.0061.

Pierce, Brooks. 2001. “Compensation Inequality." The Quarterly Journal of Economics 116:1493525. https://doi.org/10.1162/003355301753265633.

Pierce, Brooks. 2010. "Recent Trends in Compensation Inequality." Pp. 63-98 in Labor in the New Economy, edited by K.G. Abraham, J.R. Spletzer, and M. Harper. Chicago, IL: University of Chicago Press. .

Piketty, Thomas, Emmanuel Saez, and Gabriel Zucman. 2016. Distributional National Accounts: Methods and Estimates for the United States. Working paper, National Bureau of Economic Research.

Rosenfeld, Jake. 2014. What Unions No Longer Do. Cambridge, MA: Harvard University Press. https://doi.org/10.4159/harvard.9780674726215.

Semyonov, Moshe, Noah Lewin-Epstein, and William Bridges. 2011. "Explaining Racial Disparities in Access to Employment Benefits." Ethnic and Racial Studies 34:2069-95. https://doi.org/10.1080/01419871003687552.

Sørensen, Aage B. 2000. "Toward a Sounder Basis for Class Analysis." American Journal of Sociology 105:1523-58. https://doi.org/10.1086/210463. 
Tomaskovic-Devey, Donald, Catherine Zimmer, Kevin Stainback, Corre Robinson, Tiffany Taylor, and Tricia McTague. 2006. “Documenting Desegregation: Segregation in American Workplaces by Race, Ethnicity, and Sex, 1966-2003." American Sociological Review 71:56588. https://doi.org/10.1177/000312240607100403.

U.S. Department of Labor, and Bureau of Labor Statistics. 2017. National Compensation Survey: Employee Benefits in the United States, March 2017. Bulletin 2787. Washington, DC: US Department of Labor and Bureau of Labor Statistics.

Weeden, Kim, and David Grusky. 2014. "Inequality and Market Failure." American Behavioral Scientist 58:473-91. https://doi .org/10.1177/0002764213503336.

Western, Bruce, and Jack Rosenfeld. 2011. "Unions, Norms, and the Rise in U.S. Wage Inequality." American Sociological Review 76:513-37. https://doi .org/10.1177/ 0003122411414817.

Western, Bruce, and Becky Petit. 2005. "Black-White Wage Inequality, Employment Rates, and Incarceration." American Journal of Sociology 111:553-78. https ://doi .org/10 . 1086/ 432780.

Wright, Erik O. 1997. Class Counts: Comparative Studies in Class Analysis. Cambridge, UK: Cambridge University Press.

Wright, Erik, and Rachel Dwyer. 2003. "The Patterns of Job Expansions in the USA: A Comparison of the 1960s and 1990s." Socio-Economic Review 1:289-325. https://doi. org/10.1093/soceco/1.3.289.

Acknowledgements: We thank the United States-Israel Binational Science Foundation for its partial support of this project. Earlier versions of this article were presented at the summer meeting of the International Sociological Association Research Committee on Social Stratification and Mobility (in 2017) and the Intergenerational Mobility and Income Inequality Workshop held at the University of Haifa (in March 2018). We thank Yitchak Haberfeld and the participants in these meetings for their comments. We gratefully acknowledge the support of the Bureau of Labor Statistics (BLS) and its staff, who facilitated this research with generosity and patience. The research was conducted with restricted access to Bureau of Labor Statistics data. The views expressed in any publication resulting from an analysis of these data do not necessarily reflect the views of the BLS. Additionally, the views expressed herein are those of the authors and do not necessarily reflect the views or policies of the United States Department of Labor or any agency within it.

Tali Kristal: Department of Sociology, University of Haifa. E-mail: kristal@soc.haifa.ac.il. Yinon Cohen: Department of Sociology, Columbia University. E-mail: yc2444@columbia.edu.

Edo Navot: United States Department of Labor. E-mail: navot.edo@dol.gov. 